\title{
Mot1, a global repressor of RNA polymerase II transcription, inhibits TBP binding to DNA by an ATP-dependent mechanism
}

\author{
David T. Auble, ${ }^{1}$ Karin E. Hansen, ${ }^{2}$ Chris G.F. Mueller, ${ }^{2}$ William S. Lane, ${ }^{3}$ Jeremy Thorner, ${ }^{2}$ and \\ Steven Hahn ${ }^{1}$ \\ ${ }^{1}$ Fred Hutchinson Cancer Research Center, Seattle, Washington 98104 USA; ${ }^{2}$ Division of Biochemistry and Molecular \\ Biology, Department of Molecular and Cell Biology, University of California, Berkeley, California 94720 USA; ${ }^{3} \mathrm{Harvard}$ \\ Microchemistry Facility, Harvard University, Cambridge, Massachusetts 02138 USA
}

\begin{abstract}
Basal transcription of many genes in yeast is repressed by Mot1, an essential protein which is a member of the Snf2/Swi2 family of conserved nuclear factors. ADI is an ATP-dependent inhibitor of TATA-binding protein (TBP) binding to DNA that inhibits transcription in vitro. Here we demonstrate that ADI is encoded by the MOT1 gene. Mutation of MOT1 abolishes ADI activity and derepresses basal transcription in vitro and in vivo. Recombinant Mot 1 removes TBP from DNA and Mot1 contains an ATPase activity which is essential for its function. Genetic interactions between Mot1 and TBP indicate that their functions are interlinked in vivo. These results provide a general model for understanding the mechanism of action of a large family of nuclear factors involved in processes such as transcription and DNA repair.
\end{abstract}

[Key Words: transcription; MOT1; repressor; Saccharomyces cerevisiae ; TBP]

Received June 10, 1994; revised version accepted July 1, 1994.

Transcription by RNA polymerase II (pol II) requires a set of at least 6 general transcription factors (TFIIA, TFIIB, TFIID, TFIIE, TFIIF, and TFIIH) in addition to the multisubunit pol II enzyme itself (Zawel and Reinberg 1993). The first step in transcription complex assembly is thought to involve the binding of TFIID to a TATA box located upstream from the start site of many pol II promoters (Van Dyke et al. 1988; Buratowski et al. 1989; Cortes et al. 1992). The TFIID-DNA complex nucleates the assembly of the remaining general factors and pol II (Maldonado et al. 1990; Cortes et al. 1992; Flores et al. 1992). TFIID from animal cells consists of an evolutionarily conserved TATA-binding protein (TBP) tightly associated with a set of polypeptides (TBP-associated factors or TAFs), at least some of which are involved in mediating the response of the general transcription apparatus to activators (Dynlacht et al. 1991; Takada et al. 1992; Goodrich et al. 1993; Hoey et al. 1993; Kokubo et al. 1994). TAFs are also found in association with yeast TBP (Poon and Weil 1993). TFIIA is unusual because its requirement for transcription in vitro depends on the particular transcription system used (Cortes et al. 1992; Ranish et al. 1992; Sayre et al. 1992; Tyree et al. 1993). One interpretation of this finding is that TFIIA is a regulatory factor whose function is necessary to counteract the action of transcriptional repressors. The requirement for TFIIA in vitro would depend then on whether or not such transcriptional repressors are present.

Fractionation of extracts from human cells led to the identification of several factors that can repress transcription in vitro (Drapkin et al. 1993). Drl binds to TBP and thereby inhibits both basal and activated transcription by preventing the interaction of TFIIA and TFIIB with TFIID (Inostroza et al. 1992). Dr2 (PC3, topoisomerase I) also interacts with TBP and represses basal transcription; its inhibitory activity can be overcome by TFIIA or by transcriptional activators (Kretzschmar et al. 1993; Merino et al. 1993). Similarly, NCl and NC2 are factors that can form complexes with TBP and prevent the interaction of TFIIA and TFIIB with TBP-DNA complexes (Meisterernst and Roeder 1991; Meisteremst et al. 1991).

Factors that globally repress pol II transcription have also been identified by genetic approaches in yeast. The four NOT genes (NOT1-4) and the SUD1 gene were identified by mutations which increase basal expression of many genes in yeast (Collart and Struhl 1993, 1994; Yamashita 1993). The TSF1-6 genes were also identified as repressors which may affect the basal pol II machinery (Chen et al. 1993). Genetic and biochemical data suggest that all of these proteins define pathways for repressing transcription, although the mechanism of action of these factors is unknown. 
Using a similar genetic screen for increased basal transcription, the yeast MOT1 gene was identified by mutations that led to increased basal expression of many genes (Davis et al. 1992; Piatti et al. 1992). MOT1 is an essential gene and a recessive temperature-sensitive mutation (mot1-1) leads to increased basal expression of many genes in yeast at the permissive temperature (Davis et al. 1992). In contrast, the mot1-1 allele has comparatively little effect on highly expressed genes. MOT1 was cloned and shown to encode a large protein with sequence similarity to a family of putative helicases (Davis et al. 1992). Because loss of MOT1 function leads to increased basal transcription, the normal role of Mot1 is presumably to repress basal transcription, perhaps by employing an ATP-dependent mechanism to remove specific proteins from DNA (Davis et al. 1992).

Using a biochemical approach, an inhibitor of TBP binding to DNA was identified in yeast (Auble and Hahn 1993). This factor, termed ADI for ATP-dependent inhibitor, was shown to specifically dissociate TBP-DNA complexes in an ATP-dependent manner. The effect of $\mathrm{ADI}$ is not promoter-specific, but ADI interacts with TBP-DNA complexes in a stereospecific manner. Dissociation of TBP-DNA complexes by ADI can be blocked by TFIIA and, to a lesser extent, by TFIIB. ADI can inhibit transcription in vitro, and the inhibitory effect on transcription can also be blocked by TFIIA. Thus, ADI is a repressor of pol II transcription that functions by re- moving TBP from DNA. To further characterize ADI, the ADI polypeptide was purified and amino acid sequence was used to identify the gene encoding it. In this paper we describe experiments which demonstrate that ADI is encoded by MOT1, and that the ATPase activity of Motl is required for both its activity in vitro and its function in vivo.

\section{Results \\ Identification of the ADI polypeptide}

Previous work suggested that ADI specifically recognizes TBP-DNA complexes by interaction with particular residues on the outer surface of TBP, and also by interacting with DNA immediately upstream of the TATA sequence (Auble and Hahn 1993). To identify the polypeptide responsible for ADI activity, DNA probes were constructed with photoreactive nucleotides placed in the region of the promoter presumed to be in close proximity to ADI when bound to TBP-DNA complexes. Two probes were designed which contain the photoreactive nucleotides placed at slightly different positions (Fig. 1A, marked by u). The probes were synthesized to contain radiolabeled cytosine residues /marked by asterisks) immediately adjacent to the photoreactive nucleotides to tag any crosslinked proteins with a radiolabel. These experiments were performed using the conserved

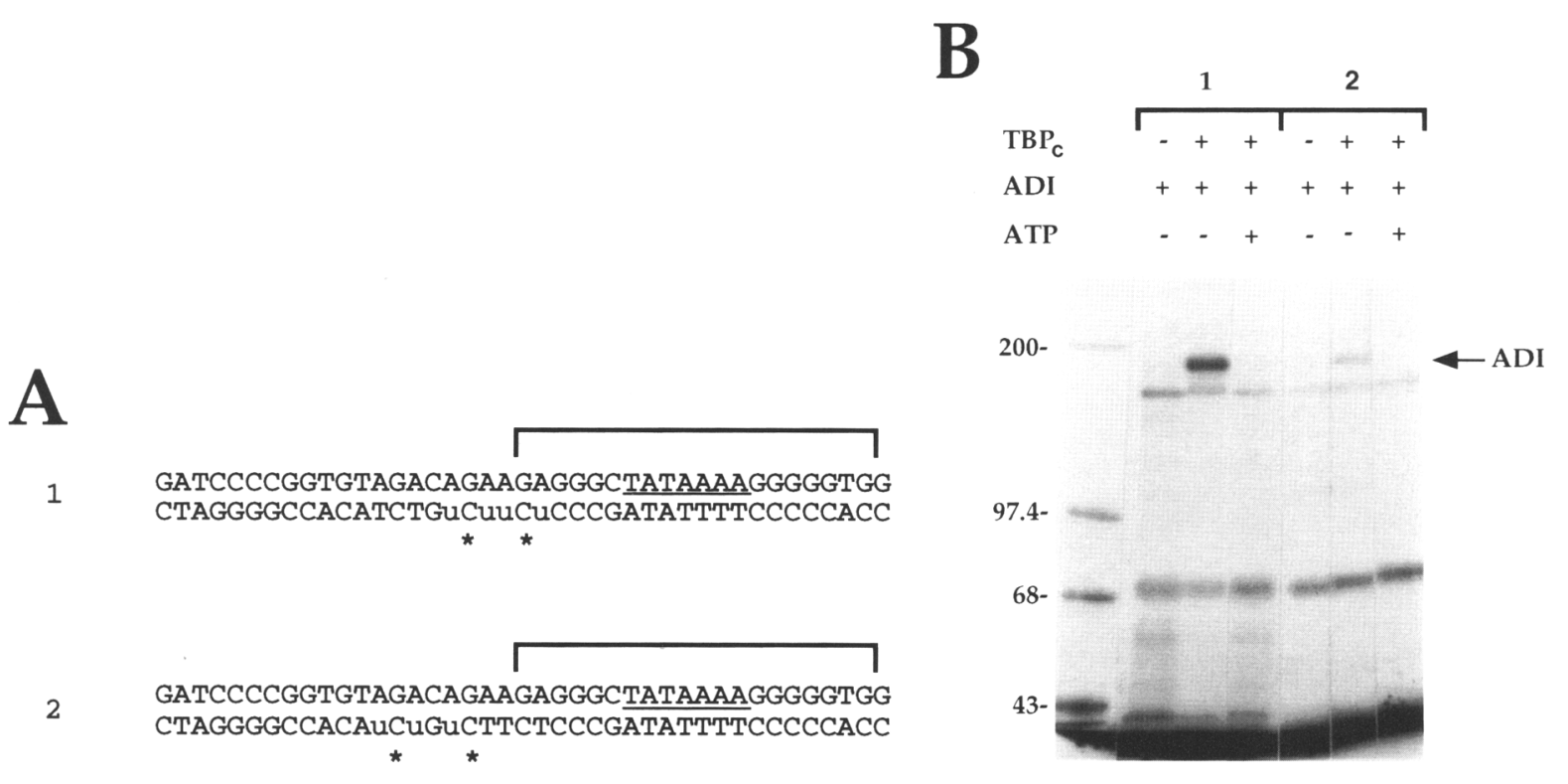

Figure 1. Photocrosslinking of the ADI polypeptide to DNA. (A) The sequences of the two DNA probes used for these experiments are shown. The promoters are variants of the adenovinus major late promoter; the TATA sequence is underlined and the region protected from nuclease digestion by TBP is shown by the brackets. The probes include the photocrosslinking nucleotide, 5 -[ $\mathrm{N}$ - $(\mathrm{p}$ azidobenzoyl)-3-aminoallyll-dUMP (denoted as " $u$ "), and adjacent radiolabeled cytosines (asterisks). These bases were positioned in the region of the promoter which is protected from nuclease digestion by ADI when it is bound to a TBP-DNA complex. $(B)$ The DNA probes (as indicated) were incubated with: $\mathrm{ADI}$; $\mathrm{ADI}$ plus $\mathrm{TBP}_{\mathrm{c}}$ (the conserved carboxy-terminal domain of yeast TBP), or ADI, TBP and ATP. Following a $25 \mathrm{~min}$ incubation in binding buffer, the reactions were treated with UV light and then either loaded directly onto a $6 \%$ nondenaturing gel (not shown) or nuclease-treated and loaded onto a $6 \%$ SDS gel. Incubation of ADI with TBP - DNA complexes results in the specific crosslinking of a polypeptide of $175 \mathrm{kD}$ apparent molecular mass to the labeled DNA (indicated by the arrow). The sizes $(\mathrm{kD})$ of radiolabeled protein size markers are shown (left). 
carboxy-terminal 180 amino acids of yeast TBP (TBP $)$ because ADI binds to $\mathrm{TBP}_{\mathrm{c}}$ more tightly than to fulllength TBP in the absence of ATP (Auble and Hahn 1993). Incubation of $\mathrm{TBP}_{\mathrm{c}}$ and partially purified ADI (Auble and Hahn 1993) with either of the two radiolabeled photoprobes resulted in the formation of both $\mathrm{TBP}_{\mathrm{c}}-$ DNA complexes and ADI-TBP - DNA ternary complexes which were detected by a gel mobility retardation assay (data not shown); upon addition of ATP, the amount of the TBP $\mathrm{P}_{\mathrm{c}}-\mathrm{DNA}$ complexes was decreased and all of the $\mathrm{ADI}-\mathrm{TBP}_{\mathrm{c}}-\mathrm{DNA}$ complexes were eliminated, as expected. After UV photocrosslinking, the products were treated with nucleases which digested the bulk of the DNA, except for short radiolabeled tags which were crosslinked to the protein. Analysis of these tagged proteins is shown in Figure 1B. Two polypeptides $(\sim 70$ and $150 \mathrm{kD}$ ) were crosslinked to the DNA whether or not $\mathrm{TBP}_{\mathrm{c}}$ or ATP was present in the reaction, indicating that these proteins are unrelated to ADI. In contrast, a polypeptide with an apparent molecular mass of $175 \mathrm{kD}$ was crosslinked to each of the DNA probes, but only in the presence of $\mathrm{TBP}_{\mathrm{c}}$. Furthermore, the appearance of the $175-\mathrm{kD}$ band was completely abolished if ATP was added prior to photocrosslinking. Because the interaction of this polypeptide with promoter DNA occurred in a manner consistent with the known behavior of ADI, this result strongly suggests that the $175-\mathrm{kD}$ polypeptide is a component of ADI. In further support of this conclusion, when column profiles from the later stages of ADI purifications were examined by SDS-PAGE and silver staining, the level of ADI activity detected correlated with the amount of a $175-\mathrm{kD}$ polypeptide present in the same fractions (data not shown).

Approximately $20 \mu \mathrm{g}$ of the $175-\mathrm{kD}$ polypeptide were purified from $1.4 \mathrm{~kg}$ of yeast cells as described in Materials and methods. After transfer to a PVDF membrane, the protein was enzymatically digested and the sequences of two derived peptides were determined unambiguously (see Materials and methods). The two peptide sequences, NTPKHPVDITESSV and NMTNSAASLATSPTSNQLNPK, were found to match exactly the deduced sequence of yeast Motl from amino acids 214-227 and 236-256, respectively.

Mot1 has several features expected of the ADI polypeptide (Davis et al. 1992; Piatti et al. 1992). First, Motl was found to be an essential protein which represses the transcription of many genes in yeast. Second, Motl is large (1867 amino acids) and contains consensus motifs for ATP binding and hydrolysis, which are embedded in a larger conserved domain of about $55 \mathrm{kD}$ (Fig. 2). Mot1 is highly related to a conserved family of proteins (the Snf2/Swi2 family) which participate in activation of transcription, DNA repair, and chromosome segregation (Fig. 2). Members of this family are present in organisms from bacteria to humans (Davis et al. 1992; Bork and Koonin 1993; Henikoff 1993). Comparison of homologous blocks of sequence from any two family members indicates that they generally share between 30 and $60 \%$ amino acid sequence identity. The presence of this large evolutionarily conserved domain in all of these proteins suggests that it provides an ATP-dependent enzymatic function that is employed for many diverse purposes in cells (see Discussion).

\section{ADI is encoded by MOT1}

Nuclear extracts were prepared from wild-type MOT1 and temperature-sensitive mot1-1 cells. These extracts

Figure 2. Mot 1 is a member of the Snf $2 /$ Swi2 family of nuclear regulatory factors. A schematic alignment of Mot 1 and several related proteins is shown. The length of each protein (number of amino acids) is shown on the right. Open boxes indicate nonconserved regions; filled boxes represent conserved sequence motifs which each share between 30 and $60 \%$ amino acid identity between any pair of the proteins listed. Motifs involved in ATP binding and hydrolysis are bracketed; the $\mathrm{K} 1303 \mathrm{~A}$ mutation is located in the aminoterminal motif and the D1408N mutation is located in the carboxy-terminal motif (see text). SNF2/SWI2 encodes an activator of transcription of many genes in yeast (Laurent et al. 1991). hSNF2L is thought to

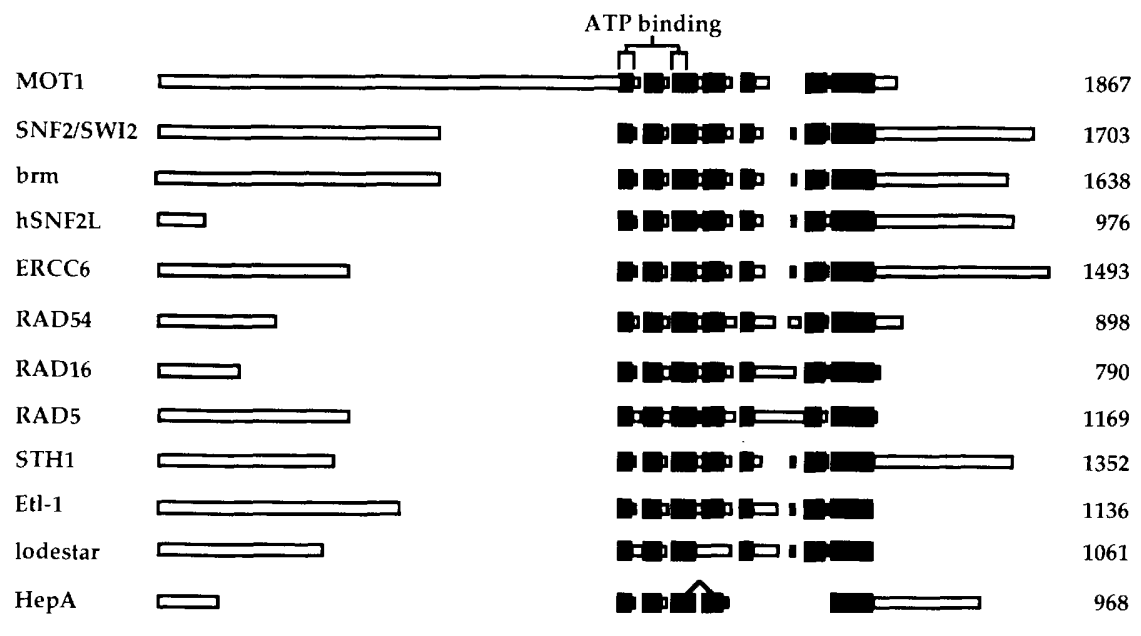
be a human homolog of Snf2/Swi2 (Okabe et al. 1992). Brahma (brm) encodes an activator of homeotic genes in Drosophila (Tamkun et al. 1992). ERCC6 (also known as CSBC) is a human gene involved in preferential repair of transcribed genes (Toelstra et al. 1992). RAD5 (Johnson et al. 1992), RAD16 (Bang et al. 1992), and RAD54 (Emery et al. 1993) are yeast genes involved in DNA repair. Drosophila lodestar encodes a function required for chromosome segregation (Girdham and Glover 1991). Etl-1 (Soininen et al. 1992) encodes a mouse developmentally-expressed protein, and STH1 (Laurent et al. 1992) is an essential yeast gene; the functions of both Etl-1 and Sthl are unknown. HepA is a gene from E. coli of unknown function (Lewis et al. 1992; Bork and Koonin 1993). The distance of 174 residues between two of the conserved motifs in HepA is greater than the distances between these homologous blocks in any of the other proteins analyzed, and is depicted as a bracket above the relevant region of HepA. 
were fractionated and tested for $\mathrm{ADI}$ activity in a gel mobility retardation assay. As shown in Figure $3 \mathrm{~A}$ (lanes $1,2)$, an extract from wild-type cells contains ADI as expected. In the absence of ATP, ADI binds to TBP-DNA complexes to produce ADI-TBP-DNA ternary complexes. In the presence of ATP, both TBP-DNA and ADI-TBP-DNA complexes are disrupted. In contrast, an extract from mot1-1 cells prepared in parallel with the wild-type extract contains no detectable ADI activity (lanes 3,4). In the absence of ATP, no ADI-TBP-DNA complexes are formed with the mot1-1 fractions, and in the presence of ATP, TBP-DNA complexes are not disrupted. Thus, even at the permissive temperature, extracts from mot1-1 cells contained no detectable ADI activity, suggesting that a functional MOT1 gene is necessary for ADI activity.

To determine if Mot 1 is sufficient for ADI activity, the MOT1 coding sequence was introduced into a plasmid, and Motl was produced by in vitro transcription and translation. As controls, the in vitro transcription and translation reactions were performed with no added DNA template or with a mutant mot1 gene containing a single amino acid change (K1303A). This residue lies within a sequence motif (GxGKT) thought to be important for ATP binding and hydrolysis (Fig. 2) because substitution of the equivalent residue in Snf2/Swi2 and Rad3 has been reported to abolish their ATPase activity, but not their ability to bind ATP (Sung et al. 1988; Laurent et al. 1993).

The in vitro transcription/ translation reactions contained ATP which could not be removed from the reaction products so the gel mobility retardation assays using the Mot 1 proteins produced in vitro contained ATP. TBP-DNA complexes were reduced about twofold upon addition of unprogrammed lysate to a binding reaction (Fig. 3B, lanes 1,2). Strikingly, however, addition of the normal Motl produced by in vitro transcription and translation resulted in the complete disappearance of the TBP-DNA complexes (Fig. 3B, lane 3). The activity of the added Mot 1 is dependent on an intact ATP-binding sequence because TBP-DNA complexes are only weakly affected by Mot 1 containing the K1303A mutation (lane 4 ), even though the wild-type and mutant proteins were produced at comparable levels (not shown). These results demonstrate that Motl is an essential component of $\mathrm{ADI}$ activity, and that the Motl polypeptide is likely to be sufficient for ADI activity.

We noted that a ternary complex composed of TBP, DNA, and the mutant Motl(K1303A) protein was not detectable in these experiments (Fig. 3B, lane 4). Genetic data described below strongly suggest that overexpressed ATPase-defective Motl can interact with TBP in vivo, but this interaction is likely difficult to detect in vitro with the low levels of Motl produced in the in vitro translation reactions. It is also possible that Motl(K1303A) does not interact with TBP-DNA complexes as strongly as wild-type Mot 1 , or that this mutant protein can still hydrolyze ATP but at a very slow rate.

\section{Mot1 has ATPase activity}

To determine whether Motl has ATPase activity, its 70$\mathrm{kD}$ conserved carboxy-terminal domain, MotlC (residues 1255-1867; Fig. 2), was expressed in Escherichia coli as a fusion to a $(\mathrm{His})_{6}$ tract to facilitate purification using nickel-chelate affinity chromatography. As a control, the same method was used to purify a mutant Mot $1 C$ protein containing a single amino acid substitution (Dl408N). This residue lies within another sequence motif (DEGH) thought to be important for ATP binding and hydrolysis (Fig. 2) because substitution of the equivalent residue in eIF-4A has been reported to abolish ATPase activity, but not the ability to bind ATP (Pause and Sonenberg 1992). As an additional control, a purification was carried out in parallel with extract from cells expressing the vector alone. Equal amounts (140 ng) of Mot1C and Mot1C(D1408N), or an equal volume of the column eluate from the vector-only control, were

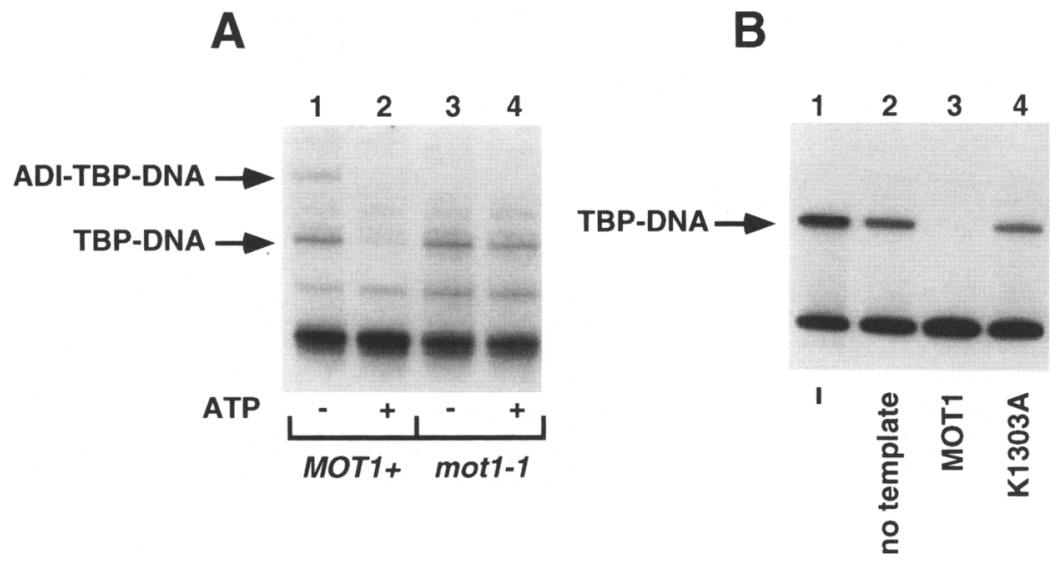

Figure 3. Mot 1 possesses ADI activity. (A) Extracts from mot1-1 cells do not contain detectable ADI activity. Nuclear extracts were prepared from wild-type MOT1 and mot1-1 mutant cells. These extracts were fractionated as described (Auble and Hahn 1993) and tested for ADI activity by a gel mobility retardation assay using a radiolabeled fragment of the adenovirus major late promoter and recombinant yeast TBP. Lane 1 , incubation of extract from MOT1 cells with TBP and DNA; lane 2, incubation of TBP, DNA, MOT1 extract plus ATP; lane 3 , incubation of TBP, DNA and extract from mot1-1 cells; and, lane 4, incubation of TBP, DNA, mot1-1 extract plus ATP. $(B)$ In vitro translated Mot1 removes TBP from DNA. Activity of in vitro translated Motl was tested by the gel mobility retardation assay. Incubation of TBP and DNA alone is shown in lane 1. Reactions in lanes 2-4 contain ATP which is present in the reticulocyte lysate. Lane 2, incubation of TBP, DNA and nonprogrammed reticulocyte lysate; lane 3 , incubation of TBP, DNA and in vitro translated Mot1; and lane 4, incubation of TBP, DNA and in vitro translated Mot 1 (K1303A). 
assayed for ATPase activity as described in Materials and methods. Neither the vector-only control nor the MotlC(D1408N) mutant protein possessed any detectable ATPase activity above the buffer background; in contrast, the Mot $1 \mathrm{C}$ protein displayed readily detectable ATPase activity (Fig. 4A). Unlike the Snf2 carboxy-terminal domain (Laurent et al. 1993), addition of single- or double-stranded DNA (with or without TATA sequences) did not significantly stimulate $(\leqslant 2$-fold) the ATPase activity of Mot1C (data not shown). Under optimal conditions of $\mathrm{pH}$ and salt concentration, the specific activity of Mot1C was $\sim 330$ pmoles of ADP formed/ $\mu \mathrm{g}$ per min, which is at least an order of magnitude higher than that reported for the Snf2 carboxy-terminal domain even upon its stimulation by doublestranded DNA (Laurent et al. 1993).

\section{ATPase activity of Mot1 is required for its function in vivo}

The D1408N mutation in the DEGH motif of Mot1C was inserted into the context of the full-length MOT1 gene. To determine if this alteration was sufficient to compromise the function of Motl in vivo, the ability of the mutant gene to complement the slow growth (at $30^{\circ} \mathrm{C}$ ) and temperature-sensitive (above $35^{\circ} \mathrm{C}$ ) phenotypes of cells carrying a chromosomal mot1-1 allele was examined. When expressed from its own promoter on a low-copy-number (centromere-containing) plasmid, the wild-type MOT1 gene was able to restore vigorous growth at $30^{\circ} \mathrm{C}$ and was able to complement the temperature-sensitive lethality of the mot1-1 cells, unlike the vector alone (Fig. 4B, cf. upper left to upper right). In contrast, when the MOT1(D1408N) mutant gene was expressed from the same vector, it was unable to complement either the slow growth of the mot1-1 cells at permissive temperature or their temperature-sensitive lethality (Fig. 4B, bottom left and right). When the centromere-containing plasmid carrying MOT1(D1408N) was introduced into MATa/MAT $\alpha$ mot1- $\triangle 2:: L E U 2 /$ MOT1 diploid cells and the resulting transformants subjected to meiosis, tetrad analysis demonstrated that the MOT1 $(D 1408 N)$ gene was also unable to complement the mot1- $\triangle 2:: L E U 2$ null mutation (data not shown). Because both the wild-type MOT1 gene and the MOT1 $(D 1408 N)$ mutant used in these experiments also carried a carboxy-terminal c-Myc epitope tag, it was possible to confirm by immunoblot analysis using anti-cMyc monoclonal antibodies (Mab 9E10) that both the normal Mot1 and the Mot1(D1408N) mutant proteins were produced at essentially identical levels (data not shown). Thus, the D1408N substitution which abolished the ATPase activity of the protein in vitro (Fig. 4A) also eliminated its ability to function in vivo (Fig. 4B).

Most strikingly, however, both the MOT1(D1408N) mutation and the other presumptive ATPase-defective mutation, MOT1(K1303A), acted as strong dominant negative alleles. When these mutant genes were carried
Figure 4. Motl possesses an ATPase activity that is required for its function in vivo. $(A)$ ATPase activity of the purified, bacterially-expressed carboxy-terminal domain of Motl. The domain (Mot 1C) of normal Motl (residues 1255-1867) that contains sequence motifs conserved in the Snf2/Swi2 family, known DNA and RNA helicases and other nucleic acid-dependent ATPases (Fig. 2), and a site-directed mutant (Mot1C D1408N) with an alteration in a putative ATP-binding element, were both expressed in E. coli and purified to near homogeneity as described in Materials and methods. The ATPase activity of samples of the eluate from the final step of purification $\left(\mathrm{Ni}^{2+}\right.$-chelate affinity chromatography) was measured by the assay method described in Materials and methods. No Enzyme, buffer only control; Vector, an equal volume of column eluate from a mock purification conducted with an extract from E. coli cells expressing empty vector; Mot $1 \mathrm{C}$, a sample (140 $\mathrm{ng}$ ) of the normal carboxy-terminal domain; and, Mot1C D1408N, a sample (140 ng) of the mutant protein. Error bars represent the range of values observed for measurements made in duplicate. $(B) \mathrm{A}$ yeast strain (JDY215b) containing the mot1-1 temperature-sensitive allele (Davis et al. 1992) was transformed with either a centromere-containing vector (pRS316) alone (upper right quadrant), or the same vector expressing the normal MOT1 gene from its own promoter (upper left quadrant), or the same vector expressing the mot1(D1408N) mutant from its own promoter (lower left and right quadrants). Transformants harboring these plasmids were streaked to single colonies on SCD-Ura plates and incubated at temperatures both permissive $\left(30^{\circ} \mathrm{C}\right)$ and restrictive $\left(35^{\circ} \mathrm{C}\right)$ for the mot $1-1$ host cell.
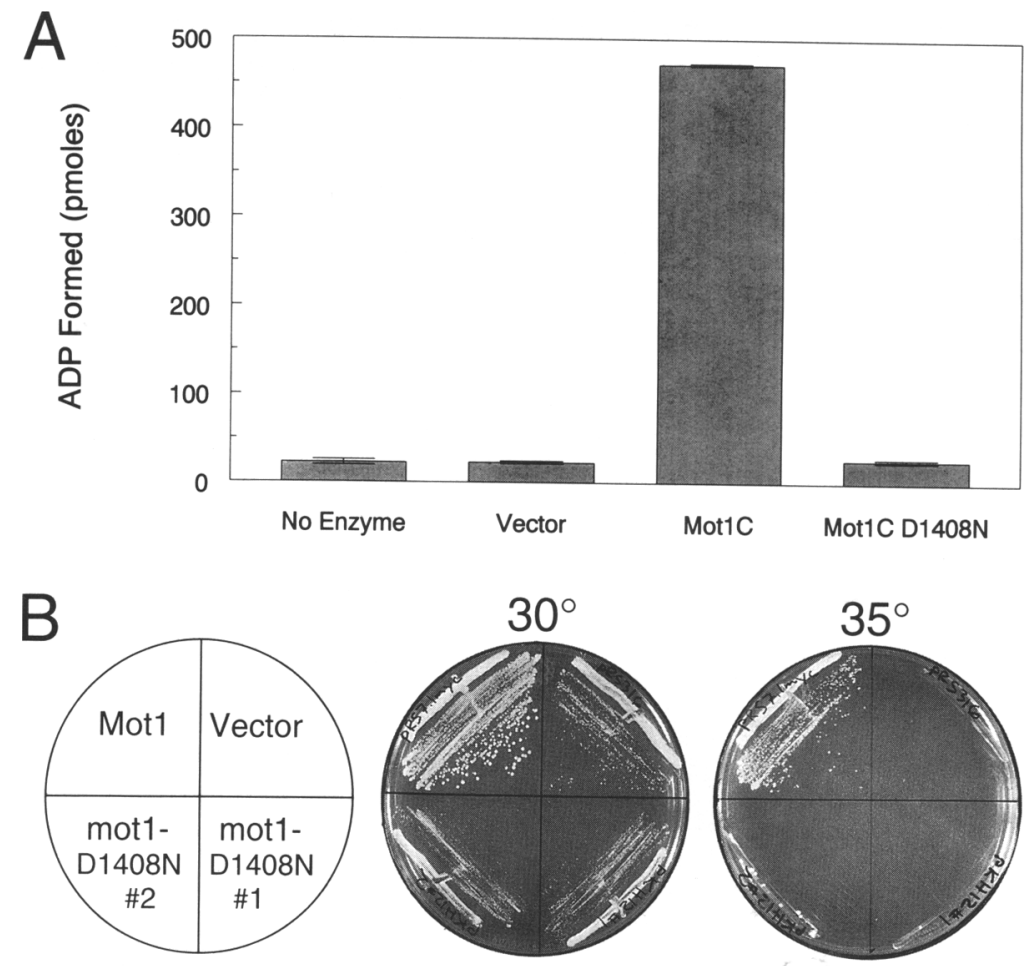
on multi-copy ( $2 \mu \mathrm{m}$ DNA-containing) plasmids and were overexpressed from the galactose-inducible GAL1 promoter in $\mathrm{MOT}^{+}$cells, growth was dramatically inhibited (Fig. 5A, lower right and left). In contrast, the presence of the vector alone or overexpression of normal MOT1 had little or no effect on the growth of wild-type cells (Fig. 5A, upper left and right). These results suggested the possibility that without ATP hydrolysis, the mutant Motl may become locked in a nonfunctional complex with TBP.

\section{Genetic interactions between MOT1 and TBP}

Because the biochemical findings presented here demonstrated that Motl is $\mathrm{ADI}$, and because it was shown previously that ADI interacts stereospecifically with TBP in vitro, we tested whether evidence for functional association of Motl and TBP in vivo could be obtained through genetic interactions between MOT1 and TBP.

Indeed, when TBP (encoded by the SPT15 gene) was constitutively over-expressed from the $A D H 1$ promoter on a multi-copy ( $2 \mu \mathrm{m}$ DNA-containing) plasmid, it had no effect on the growth of wild-type cells, regardless of whether they were overproducing normal Motl (Fig. 5B, upper half). Strikingly, however, overexpression of TBP rather efficiently suppressed the lethality caused by overproduction of the dominant-negative Mot1(D1408N) mutant (Fig. 5B, lower half). Likewise, overexpression of TFIIA lencoded by the TOA1 and TOA2 genes) from a $2 \mu \mathrm{m}$ DNA-containing plasmid also suppressed the growth inhibitory effect of the dominantnegative Mot1(D1408N) mutant, but significantly less well than TBP (Fig. 5C). Overexpression of TFIIB (encoded by the $S U A 7$ gene), also carried by a $2 \mu \mathrm{m}$ DNAcontaining plasmid, was unable to suppress the dominant negative effect of the MOT1 (D1408N) allele (data not shown).

In contrast to the ability of overproduced TBP to reverse the effect of the dominant-negative MOT1(D1408N) allele, overproduction of TBP dramatically exacerbated the slow growth phenotype of cells carrying the recessive mot1-1 mutation. In fact, mot1-1 cells transformed with the plasmid over-producing TBP grew extremely slowly and were difficult to maintain because

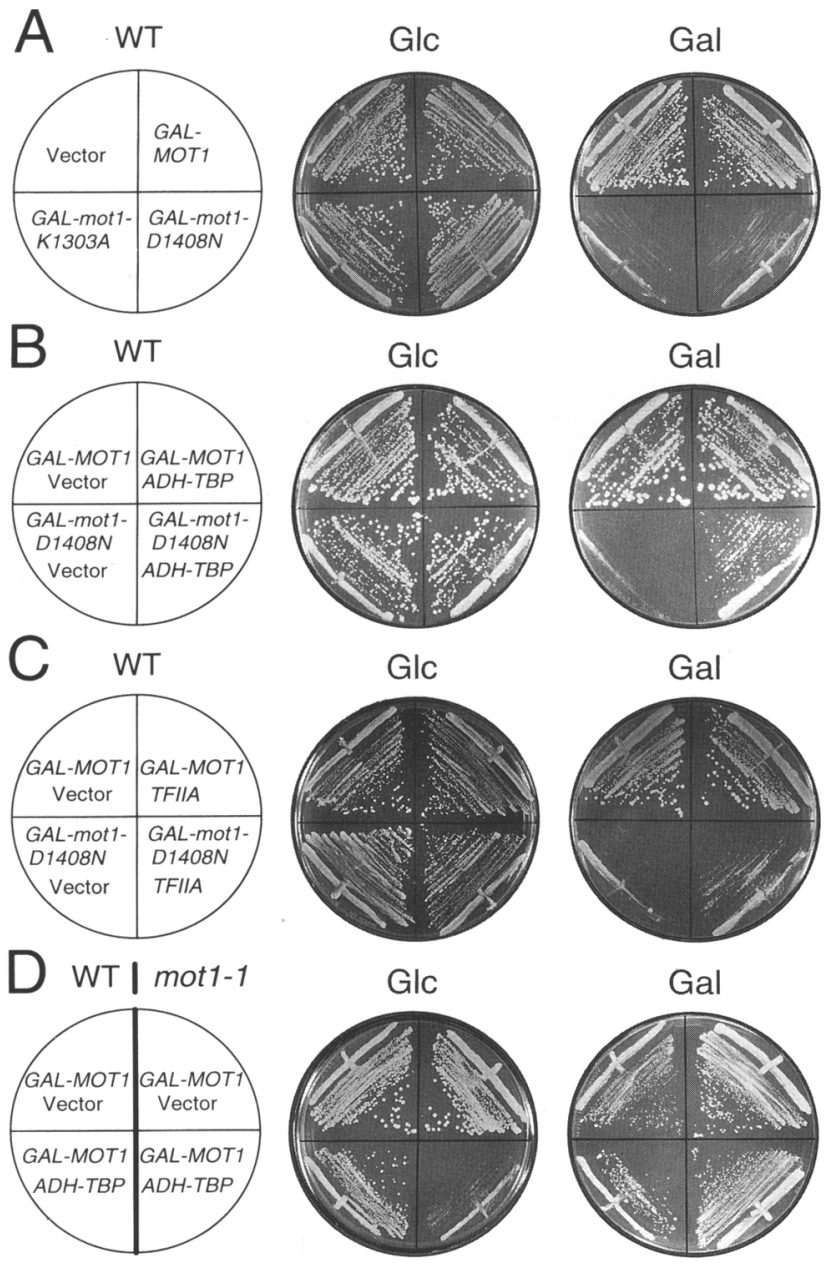

Figure 5. TBP overproduction overcomes the growth inhibitory effect of a dominant negative MOT1 allele and exacerbates the phenotype of the mot1-1 mutation. (A) A MOT1 ${ }^{+}$strain, W303-1A (WT), was transformed with either a multi-copy GAL1 promoter-containing vector (YEp352G) alone (upper left quadrant), or the same vector expressing from the GAL1 promoter either the normal MOT1 gene (upper right quadrant) or two different site-directed mot1 mutants, each containing an alteration in a sequence motif thought to be involved in ATP binding and hydrolysis, MOT1(K1303A) (lower left quadrant) and $\operatorname{MOT1}(D 1408 N)$ (lower right quadrant). Transformants harboring these plasmids were streaked to single colonies and incubated at $30^{\circ} \mathrm{C}$ either on SCD-Ura plates (Glc) for 2 days or on SCGalSuc-Ura plates (Gal) for 4 days. (B) Strain W303-1A transformed with YEp352G expressing either normal MOT1 (upper half) or the dominant negative allele, MOT1(D1408N) (lower half), were cotransformed with either a multi-copy $A D H 1$ promoter-containing vector (AAH5) alone (left side) or the same vector expressing yeast TBP (SPT15 gene product) from the $A D H 1$ promoter (right side). The transformants were then grown as in $A$ (except that the media also lacked Leu). $(C)$ Strain W303-1A transformed with YEp352G expressing either normal MOT1 (upper half) or the dominant negative allele, MOT1(D1408N) (lower half), were cotransformed with either a multi-copy vector (YEp351) alone (left side) or the same vector expressing both of the subunits of yeast TFIIA (TOA1 and TOA2 gene products) from their own promoters (right side). The transformants were then grown as in $B .(D)$ Either a mot1-1 mutant, JDY215b (right side), or its otherwise isogenic MOT1 ${ }^{+}$ parent, JDY194 (WT; left side), each harboring a plasmid (YEp352G) expressing MOT1 under control of the GAL1 promoter, were transformed with either a multi-copy $A D H 1$ promoter-containing vector (AAH5) alone (upper half) or the same vector expressing yeast TBP from the $A D H 1$ promoter (lower half). The transformants were selected initially on galactosecontaining medium (SCGalSuc-Ura-Leu plates), and then individual isolates were streaked to single colonies on either galactose-containing medium or glucose-containing medium (SCD-Ura-Leu plates) to repress expression of the plasmid-borne MOT1 gene and incubated for 4 days at a temperature $\left(30^{\circ} \mathrm{C}\right)$ otherwise permissive for the growth of the mot1-1 host cell. 
of the strong selective pressure for reversion of the mot1-1 mutation or loss of the TBP-expressing plasmid (data not shown).

To avoid this problem, and to permit a more direct test of the effect of overproduced TBP in mot1-1 mutants, both mot1-1 cells and otherwise isogenic $M O T 1^{+}$cells were first transformed with a plasmid expressing normal MOT1 from the GAL1 promoter and selected on galactose-containing plates. These transformants were then cotransformed on galactose-containing medium with the plasmid constitutively overexpressing TBP under control of the $A D H 1$ promoter or the corresponding vector. To determine the effect of TBP overexpression, the cells were then streaked to single colonies on glucose-containing plates to repress transcription of the plasmidborne copy of normal MOT1. As anticipated, in the absence of normal Motl expression, overproduction of TBP severely inhibited the growth of mot1-1 mutants (Fig. $5 \mathrm{D}$, right side), whereas TBP overexpression had no effect on the growth of the $M O T 1^{+}$cells (Fig. 5D, left side).

\section{MOT1 represses pol II but not pol I and pol III transcription in vitro}

TBP is required for transcription by all three nuclear RNA polymerases. Because Motl is targeted to TBPDNA complexes, it was possible that Motl affects the expression of genes transcribed by RNA polymerases I and/or III, as well as those transcribed by pol II. To test the specificity of Mot1, nuclear extracts were prepared from $\mathrm{MOT1}^{+}$and mot1-1 cells, and these were used for in vitro transcription experiments. As assayed by primer extension, basal pol II transcription was elevated between 5- and 15-fold when transcript levels produced in extracts from mot1-1 cells were compared to those produced in extracts from wild-type cells (Fig. 6A). This effect was not promoter-specific because basal expression from each of three different pol II promoters was affected similarly. In contrast, levels of activated transcription stimulated by Gal4-VP16 were similar in MOT1 and mot1-1 extracts (Fig. 6B).

Similar results were obtained in vivo using reporter plasmids in which yeast promoters were used to drive the expression of $E$. coli $\beta$-galactosidase. It had been shown previously using hybridization analysis to blots of poly $(\mathrm{A})^{+}$RNA that basal expression, but not activated transcription, of a number of genes is markedly elevated in the mot1-1 mutant (Davis et al. 1992). To address what promoter elements might be responsible for mediating the repressive effect of Mot 1, matched sets of four different promoters, either containing or lacking their known upstream activation sequences (UAS), were fused to $l a c Z$ and introduced on multi-copy plasmids into $M O T 1^{+}$and mot1-1 cells. In all cases, removal of the UAS elements greatly lowered the level of transcription, as expected (Table 1). However, for three of the four promoters examined (the glucose-regulated $C Y C 1$ promoter, the phosphate-regulated PHO5 promoter, and the relatively constitutive $M F \mathbf{a} 2$ promoter), expression from the TATA-containing basal elements of these UAS-less con-
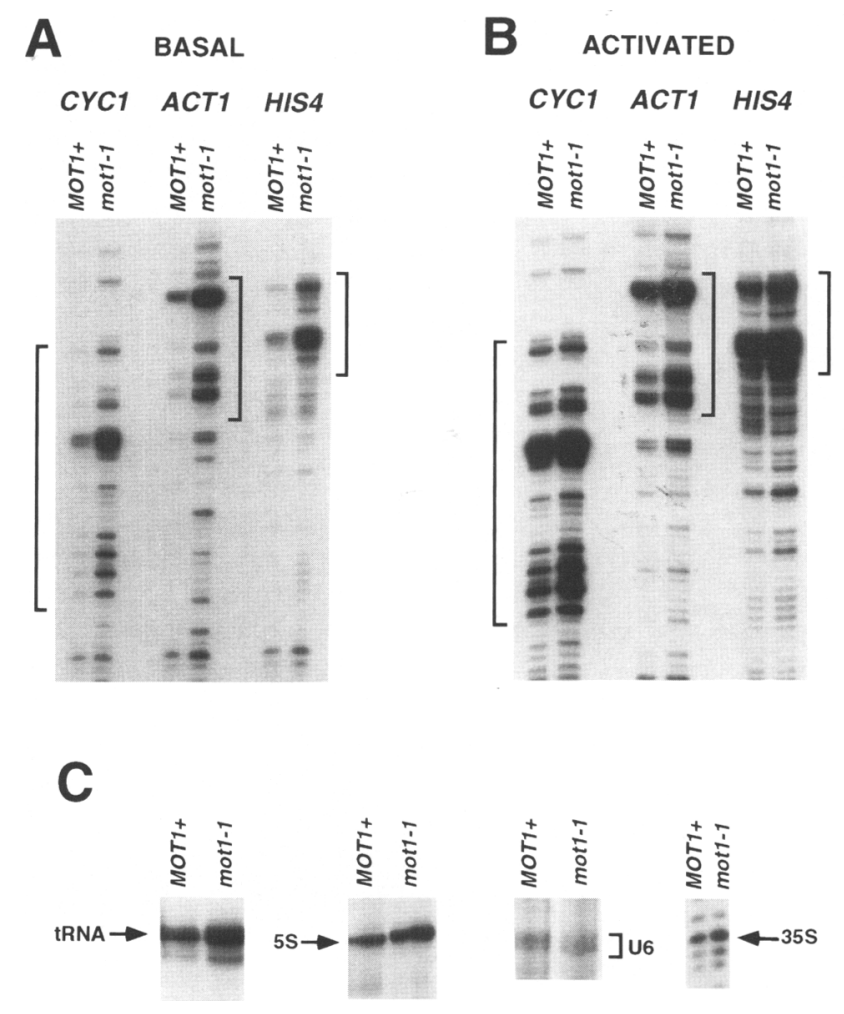

Figure 6. Motl is an RNA polymerase II-specific transcription factor. In vitro transcription experiments were performed using nuclear extracts obtained from wild-type MOT1 or mot1-1 mutant cells, as indicated. (A) Basal RNA polymerase II transcription from the CYC1, ACT1, and HIS4 promoters is shown. Correctly initiated transcripts detected by primer extension are bracketed. (B) RNA polymerase II transcription from the CYC1, $A C T 1$, and HIS4 promoters activated by Gal4-VP16 is shown. Correctly initiated transcripts are bracketed. (C) Transcription of sup4 tRNA, 5S, U6 and 35S templates is shown. Pol I transcripts were detected by $\mathrm{Sl}$ nuclease protection and pol III was assayed by run-off transcription.

structs was dramatically affected in the mot1-1 cells, increasing 87 -fold, 4-fold, and 15 -fold, respectively (Table 1). These differences are not attributable to plasmid copy number because the plasmid copy number differs less than twofold between MOT1 and mot1-1 cells (Davis et al. 1992). In contrast, when basal expression was elevated by the presence of a UAS, the change in transcription in mot1-1 cells was small. The pheromoneinducible FUS1 promoter (with or without its UAS) was found to be nonresponsive to the mot1-1 mutation. In the absence of a UAS, $\beta$-galactosidase levels driven by the FUS1 promoter were nearly undetectable. Because the absence of fully functional Motl significantly increased gene expression driven by the basal elements of several different promoters that are normally under diverse types of regulatory controls, these observations are consistent with a role for normal Motl in repressing expression at TATA sequences rather than elsewhere within these promoters.

In contrast to the effects of the mot1-1 mutation on 
Table 1. Expression of promoter-lacZ fusions in MOT1 and mot1-1 cells

\begin{tabular}{|c|c|c|c|c|c|}
\hline \multirow[b]{2}{*}{ Carbon source $^{\mathrm{a}}$} & \multirow[b]{2}{*}{ Vector } & \multirow[b]{2}{*}{ Promoter } & \multicolumn{2}{|c|}{$\beta$-Galactosidase activity ${ }^{b}$} & \multirow{2}{*}{$\begin{array}{c}\text { Change } \\
\text { fold }(+ \text { or }-1\end{array}$} \\
\hline & & & MOT1 & $\operatorname{mot} 1-1$ & \\
\hline Glycerol-lactate & pLG $\Delta-312 S$ & CYC1 & $3356 \pm 102$ & no growth & - \\
\hline Glycerol-lactate & pLG $\Delta-178$ & $\triangle U A S-C Y C 1$ & $1.3 \pm 0.45$ & no growth & - \\
\hline Glucose & pLG $\Delta-312 S$ & CYC1 & $956 \pm 102$ & $4141 \pm 873$ & $4(+)$ \\
\hline Glucose & pLG $\Delta-178$ & $\triangle U A S-C Y C 1$ & $0.59 \pm 0.14$ & $52 \pm 9.4$ & $87 i+1$ \\
\hline Glucose & pMH313 & PHO5 & $50 \pm 22$ & $57 \pm 8.2$ & 0 \\
\hline Glucose & pMH324 & $\triangle U A S-P H O 5$ & $12 \pm 4.3$ & $50 \pm 10$ & $4(+)$ \\
\hline Glucose & pCM100 & $M F \mathbf{a} 2$ & $3600 \pm 524$ & $2114 \pm 208$ & $2(-1$ \\
\hline Glucose & pCM100.1 & $\triangle U A S-M F \mathbf{a} 2$ & $3.0 \pm 1.3$ & $44 \pm 9.5$ & $15 i+1$ \\
\hline Glucose & pCM101 & FUS1 & $4.1 \pm 0.73$ & $7 \pm 1.5$ & 0 \\
\hline Glucose & pCM101.1 & $\Delta U A S-F U S 1$ & $0.2 \pm 0.0$ & $0.2 \pm 0.0$ & 0 \\
\hline Glucose & 一 & - & $0.0 \pm 0.0$ & $0.0 \pm 0.0$ & 0 \\
\hline
\end{tabular}

${ }^{a}$ Cells were grown in minimal medium containing $2 \%$ glucose or in minimal medium containing $3 \%$ glycerol and $2 \%$ DL-lactate. balues given represent the averages ( \pm S.D. of the mean) for at least two or three independent measurements of specific activity, each conducted in triplicate. Specific activity is expressed as nmoles of ONPG cleaved per min/mg of protein at $28^{\circ} \mathrm{C}$; $1 \mathrm{nmole}$ of o-nitrophenol gives an $A_{420}=0.0045$ (Miller 1972).

pol II transcription, transcription of a pol I gene (35S rRNA) and two pol III genes (tRNA and 5S rRNA) was enhanced only slightly ( $\leqslant 2$-fold) when extracts from mot $1-1$ cells were compared to extracts from MOT $1^{+}$ cells (Fig. 6C). It is possible that MOT1 has only a weak effect on pol I and pol III genes because they are controlled by very strong promoters. The yeast U6 gene was weakly but detectably transcribed by RNA polymerase III in these extracts and the levels of transcription were the same in extracts from MOT1 and mot1-1 cells. Although the U6 gene is transcribed by RNA polymerase III, it contains a functionally important TATA box which binds TBP (Eschenlauer et al. 1993; Joazeiro et al. 1994). Taken together, these results suggest that Motl is an RNA polymerase II-specific transcriptional repressor and the presence of a TATA box is not necessarily sufficient to confer regulation by Motl.

\section{Discussion}

\section{Mot1 represents a novel type of transcriptional repressor}

Studies on repression of transcription independently applying biochemical and genetic methods have led to identification of the same factor. ADI was originally detected as an ATP-dependent activity that can remove TBP bound to DNA and that represses transcription in vitro. MOT1 was identified by a mutation which caused derepression of the transcription of many genes in yeast. Motl is essential for cell viability and its sequence contains consensus motifs involved in ATP binding and hydrolysis.

The evidence presented here strongly suggests that $\mathrm{ADI}$ and Motl are identical and these results provide insight about the molecular mechanism of action of Mot1. First, extracts from cells containing a temperature-sensitive allele (mot1-1) do not contain detectable ADI activity. Second, loss of ADI activity is correlated with increased basal transcription of genes transcribed by pol II both in vivo and in vitro. Third, like the specificity observed for association of ADI and TBP in vitro (Auble and Hahn 1993), MOT1 and TBP interact genetically in vivo, with TBP overexpression enhancing the phenotype of the recessive mot1-1 mutation and suppressing the phenotype of the dominant MOT1(D1408N) and MOT1 $(K 1303 A)$ mutations. Fourth, Mot 1 contains an ATPase activity which is essential for its function both in vivo and in vitro. Finally, in vitro translated Motl can dissociate TBP from DNA in an ATP-dependent manner, just like ADI. It is formally possible that another required component of $\mathrm{ADI}$ is present in the reticulocyte lysate but we think this is unlikely.

Motl functions to repress basal and weakly activated transcription, but has little or no effect on highly transcribed genes. For example, transcription in vivo of the strongly expressed calmodulin promoter (Davis et al. 1992) and in vitro transcription stimulated by Gal4 VP16 (Fig. 6) are not significantly elevated in the absence of MOT1 function. Likewise, basal transcription in vitro can be repressed by histones, and this chromatin-mediated repression can be overcome by the presence of transcriptional activators (Durrin et al. 1991; Laybourn and Kadonaga 1992, Workman and Kingston 1992). Mammalian repressors of transcription identified biochemically, such as $\mathrm{NC1}, \mathrm{NC2}$, and topoisomerase I, also resemble Motl in that these factors selectively repress basal but not activated transcription (Meisterernst and Roeder 1991; Meisterernst et al. 1991; Kretzschmar et al. 1993; Merino et al. 1993). However, despite this superficial similarity, the mammalian repressors characterized to date and histone-mediated repression are likely to act by mechanisms that are distinct from Motl because histones and these mammalian factors have no known homology to Motl and do not appear to require ATP for their function. Thus, we propose that Motl represents a paradigm for a previously unknown type of transcriptional repressor whose function is to keep basal tran- 
scription low by interacting directly with TBP bound to DNA and catalyzing its removal at the expense of ATP hydrolysis.

\section{The essential function of Mot1}

Cells carrying mot1s null alleles are inviable. Cells carrying the mot1-1 temperature-sensitive allele grow slowly even at the permissive temperature. Why is MOT1 function essential for growth and viability?

The in vitro studies presented here corroborate the conclusion from previous genetic analysis that mot 1-1 cells are deficient in Mot 1 activity in vivo. The fact that mot1-1 cells cannot tolerate an elevated level of TBP (Fig. 5D) suggests that one essential role for Mot l action may be to prevent the indiscriminate binding of TBP to inactive promoters, thus preventing inappropriate gene expression. Conversely, the ATPase-defective MOT1 alleles are dominant negative apparently because they sequester TBP and/or promote promiscuous binding of TBP to the TATA box. These mutant proteins are dominant only when overexpressed from a strong promoter on a high copy number plasmid and are suppressed by increased levels of TBP. Mot1-TBP-DNA ternary complexes were not observed in vitro using the Mot1(K1303A) mutant (Fig. 3B), but the in vitro translation reactions contain low levels of Motl activity and Motl-TBPDNA ternary complexes are difficult to detect in reactions that contain low levels of Mot1 (Auble and Hahn 1993).

\section{Models for Mot1 function in transcriptional regulation}

Because the binding of TFIID to a promoter is the first step in the formation of a transcription initiation complex, it is a likely point for gene regulation. TFIIA can block the action of Motl in vitro (Auble and Hahn 1993), and TFIIA also partially suppresses the growth defect in cells harboring dominant-negative MOT1 alleles (Fig. 5C). Mot 1-mediated transcriptional repression can also be overcome by transcriptional activators, like Gal4VP16. One of the functions of site-specific activators might be to recruit TFIIA as a means to block Mot 1 action. On the other hand, transcriptional activators or other general factors may interact directly with TBP /or via other proteins) to block the action of Mot1. Poon et al. showed by immune precipitation that Mot 1 is one of several TBP associated factors (TAFs) (Poon and Weil 1993; D. Poon, A.M. Campbell and P.A. Weil, pers. comm.) Because Motl has a specific effect on pol II transcription in vitro, we presume that it is a pol II-specific TAF.

One model for the role of Motl in repressing gene expression is that it makes the binding of TFIID to DNA rate-limiting by increasing the dissociation rate of TBP from the TATA element (Fig. 7A). In vitro, TBP-TATA complexes are quite stable (Hahn et al. 1989; Lieberman et al. 1991). Presumably, in the absence of Motl, the dissociation of TFIID from DNA would also be slow. In
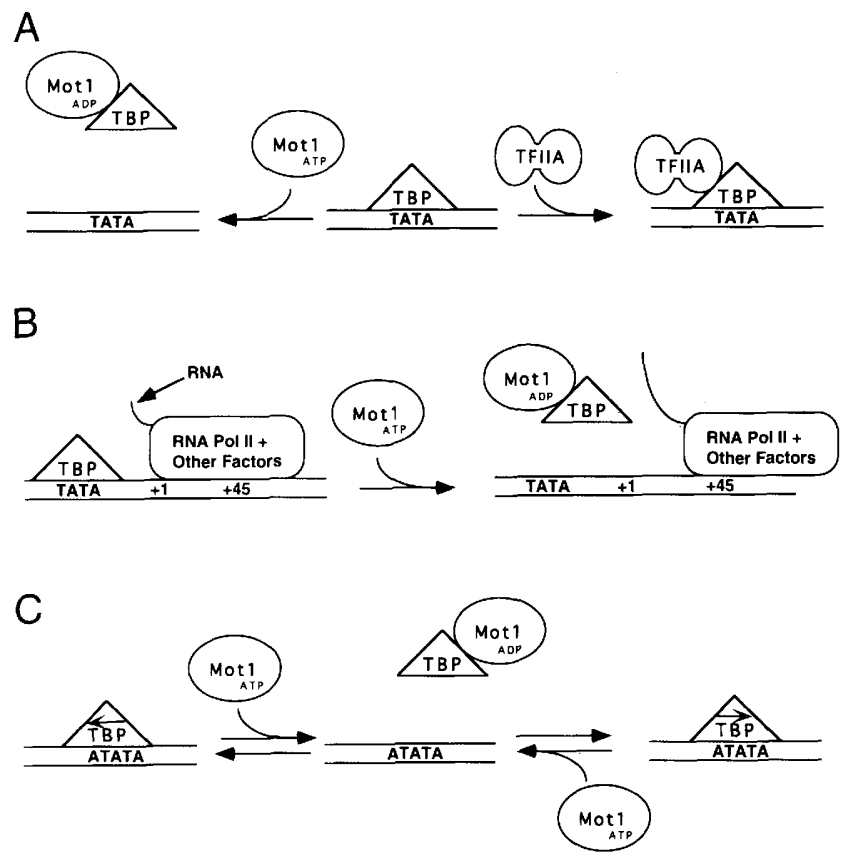

Figure 7. Models for Mot1 function in vivo. $(A) \mathrm{TBP}$ binds to the TATA box at promoters transcribed by RNA polymerase II (center). Mot1 removes TBP from DNA in an ATP-dependent manner (left). If TFIIA binds to TBP first, however, Motl is prevented from functioning (right). Motl action is also blocked by strong transcriptional activators. In vivo, TBP is an essential component of TFIID, a large multi-subunit complex. $|B|$ Mot 1 may remove TBP from the promoter in an ATP-dependent manner once RNA polymerase II transcription has begun. (C) An additional, but not exclusive, role for Mot 1 may be to assist in correctly orienting TBP at symmetrical TATA boxes by catalyzing dissociation of TBP from the promoter in an ATP-dependent manner, thus allowing TBP to rebind in a mode productive for transcription initiation.

the presence of Motl, however, TFIID binding to promoters in vivo would be unstable unless TFIID binding were stabilized by interaction with another factor (such as TFIIA, other basal factors, or a transcriptional activator) that is able to block Mot1 action (Fig. 7A). This model could explain how Motl selectively represses basal transcription. Testing of this model awaits purification of yeast TFIID complexes that contain Motl.

Another possible role of Motl in regulating gene expression is to accelerate dissociation of TFIID from DNA once the elongating polymerase has disengaged from the preinitiation complex (Fig. 7B). In vitro studies with highly purified and/or recombinant basal transcription factors demonstrate that TBP remains at the promoter after pol II moves along the template (D. Reinberg, pers. comm.). In contrast, in vitro studies in crude extracts suggest that TFIID, as well as other factors, dissociate as pol II elongates a chain (Kadonaga 1990). Mot1-mediated dissociation of TFIID after transcription initiation has occurred would allow the rebinding of TFIID to be a regulated step for subsequent rounds of transcription initiation. 
A related function for Mot 1 may involve facilitating the correct polarity of TBP binding to DNA (Fig. 7C). Many TATA sequences are symmetrical, but TBP is asymmetric. The orientation of TBP binding with respect to the promoter is critical for proper gene expression (Nagawa and Fink 1985). TBP bound in the incorrect orientation at a symmetrical TATA would interfere with transcription because TBP-DNA complexes dissociate slowly. Mot l could, however, accelerate dissociation of incorrectly positioned TBP and thereby provide another opportunity for TBP binding in the correct orientation (Fig. 7C). Further genetic and biochemical studies should allow testing of these various models for Mot 1 function.

In view of the evolutionary conservation of the pol II transcription machinery, and the fact that Motl belongs to a highly conserved family, it would not be surprising if Motl itself has been conserved. Although no Motl homolog has yet been identified as a pol II TAF in humans or flies, it may be more weakly associated with the TFIID complex than other TAFs. In fact, Mot1 is readily dissociated from yeast TBP by ion exchange chromatography (Auble and Hahn 1993).

\section{Function of Snf2/Swi2 family members}

Mot1 is a member of the family of Snf2/Swi2-related regulatory factors. These factors all contain a large $/ \sim 550$ residue) conserved domain, but are largely divergent outside of this conserved region (Fig. 2). Proteins containing this highly conserved domain are found in organisms as diverse as bacteria and humans. Genetic and biochemical data suggest that Snf2/Swi2 is part of a large complex required for expression of many yeast genes and that it acts by overcoming repression by nucleosomes (Happel et al. 1991; Hirschhorn et al. 1992; Laurent and Carlson 1992; Peterson and Herskowitz 1992; Winston and Carlson 1992; Cairns et al. 1994). Drosophila brm is required for activation of a set of homeotic genes (Tamkun et al. 1992). ERCC6/CSBC, Rad54, Rad16, and Rad5 are involved in repair of DNA damage (Bang et al. 1992; Johnson et al. 1992; Toelstra et al. 1992; Emery et al. 1993|. Drosophila lodestar is required for proper segregation of chromosomes (Girdham and Glover 1991). Finally, Motl is a repressor of basal transcription.

How can these highly related proteins have such diverse roles in cellular regulation? We speculate that the conserved region encodes a catalytic domain that uses ATP for a conserved enzymatic function. Consistent with this view, swapping of the conserved domains from two other family members for the corresponding segment in Snf2 restored partial Snf2 function (Khavari et al. 1993; Laurent et al. 1993). By analogy with the mechanism we have described here for Motl, we propose that the conserved domain in each of the Snf2/Swi2 family members functions to remove proteins from DNA at the expense of ATP hydrolysis. ATPase activity is essential for the functions of Mot1 as well as Snf2/Swi2 and Brg1, a human Snf2/Swi2 family member (Khavari et al. 1993; Laurent et al. 1993). We propose that the different proteins have different functions because they are targeted to different protein-DNA complexes. The nonconserved regions of these molecules could be responsible for the unique protein-protein interactions that allow them to dissociate different protein-DNA complexes in an ATPdependent manner for different purposes. For example, genetic and biochemical data suggest that Snf2 alters chromatin structure (Winston and Carlson 1992); the possible ATP-dependent removal of histones from DNA by the Snf 2 complex is a function entirely analogous to the ATP-dependent removal of TBP from DNA that is carried out by Mot1. Just as Mot 1 appears to be a component of the TFIID complex, genetic and biochemical data also suggest that Snf2 functions in a large complex with other proteins important for transcriptional activation (Laurent and Carlson 1992; Cairns et al. 1994). Similarly, ERCC6/CSBC and the Rad proteins could be targeted to repair enzymes bound to DNA at sites of DNA damage where the removal of proteins may be an obligate part of the repair process. Thus, the nonconserved regions of Snf $2 / S w i 2$ family members may mediate their interactions with other proteins that determine the target specificity of their action. It is also possible that the target specificity of Snf2/Swi2 family members overlaps with the conserved region as the replacement of the Snf2/Swi2 conserved region with the conserved region from the related Drosophila ISWI gene does not restore Snf2/Swi2 function (Elfring et al. 1994).

It was proposed initially that all members of the extended Snf2/Swi2 family might be ATP-dependent helicases (Davis et al. 1992; Laurent et al. 1992; Bork and Koonin 1993). However, a more recent computer analysis suggests that Motl and the other Snf2/Swi2 family members are distinct from helicases because they share their highest degree of sequence similarity with viral factors that appear to lack helicase activity in vitro (Henikoff 1993). Moreover, the Snf2 carboxy-terminal domain (Laurent et al. 1993) and purified ADI (Auble and Hahn 1993) apparently do not have detectable helicase activity in vitro. However, it is possible that ATP hydrolysis by Mot1, Snf2, and the other related factors stimulates dissociation of protein-DNA complexes by inducing structural alterations in DNA, such as local transient unwinding.

Apart from its ability to hydrolyze ATP, Motl is the first Snf2/Swi2 family member whose biochemical activity-dissociation of TBP from TATA-containing DNA-has been elucidated. Further studies are required to determine how Motl catalyzes removal of TBP from DNA and whether this mechanism of protein-DNA dissociation is conserved among the other family members.

\section{Materials and methods}

Strains and growth conditions

Yeast strains used in this study were W303-1A (MATa MOT1 ${ }^{+}$ ura3-1 his3-11,15 ade2-1 leu2-3,112 trp1-1 can1-100|, JDY194 (MATa MOT1 ${ }^{+}$ura3-52 his4-519 leu2-3,112 trp1-1 can1-101) and JDY215b (mot1-1, otherwise isogenic to JDY194) (Davis et al. 1992). Yeast cells were propagated and DNA-mediated transformation and other genetic manipulations were performed as 
recommended (Sherman et al. 1986). GalSuc media contained $2 \%$ galactose and $0.2 \%$ sucrose as the carbon sources; glucose media contained this carbon source at $2 \%$.

\section{Purification of $A D I$}

All buffers contained protease inhibitors as described previously (Auble and Hahn 1993) and fractionation was performed using siliconized glassware whenever possible. ADI was purified from yeast nuclear extract through the BioRex 70 step essentially as described (Auble and Hahn 1993). Fractions containing the peak of ADI activity were pooled and the conductivity was adjusted to that of HA buffer (30 mM HEPES at pH 8, 2 mM EDTA, 10\% glycerol, $0.1 \%$ Brij $58,1 \mathrm{~mm}$ DTT) plus $0.1 \mathrm{~m}$ potassium acetate by dialysis and dilution. On average, $\sim 0.6 \mathrm{mg}$ of protein was obtained from $450 \mathrm{~g}$ wet weight of late-exponential phase yeast cells. This material was loaded onto a $0.5 \mathrm{ml}$ Macroprep CM column and eluted with an $8.5 \mathrm{ml}$ gradient of potassium acetate from $0.1-0.7 \mathrm{M}$ in HA. ADI eluted at $\sim 0.3 \mathrm{M}$ salt. To obtain enough ADI polypeptide for amino acid sequence analysis (see below), ADI activity from three separate preparations $(119,000$ units of activity, $1.86 \mathrm{mg}$ / was pooled and the protein was precipitated with TCA. The pooled protein was then fractionated on a Superose- 12 column in $6 \mathrm{M}$ guanidine $\mathrm{HCl}, 50 \mathrm{~mm}$ Tris- $\mathrm{HCl}$ (pH 8), 0.1\% Brij 58 and $1 \mathrm{~mm}$ DTT. The fractions containing the ADI polypeptide were identified by SDS-PAGE followed by silver-staining. The Superose- 12 fractions containing the ADI polypeptide were pooled and dialyzed against $30 \mathrm{~mm}$ Tris-acetate $(\mathrm{pH} 81,2 \mathrm{~mm}$ EDTA, $10 \%$ glycerol, $25 \mathrm{~mm}$ potassium acetate, $0.1 \%$ Brij $58,1 \mathrm{~mm}$ DTT. The dialyzed protein was then precipitated with TCA and fractionated on a $5 \%$ polyacrylamide gel. The ADI material was transferred to a PVDF membrane (Bio-Rad) in Towbin transfer buffer (Towbin et al. 1979) (without SDS). The ADI polypeptide was localized by staining the PVDF membrane with $0.1 \%$ Ponceau $S$ as described (Ranish et al. 1992) and excised for further analysis.

\section{Trypsin digestion, HPLC separation and protein sequencing}

PVDF slices containing ADI were submitted to in situ digestion with trypsin (Fernandez et al. 1992). The resulting peptide mixture was separated by narrow-bore high performance liquid chromatography using a Vydac C18 reverse-phase column 12.1 $\mathrm{mm} \times 150 \mathrm{~mm}$ ) on a Hewlett-Packard 1090 HPLC with a 1040 diode array detector. Optimum fractions were chosen based on symmetry, resolution, ultraviolet absorbance spectra, and submitted to automated Edman degradation on an Applied Biosystems 477A protein sequencer. Strategies for peptide selection, reverse-phase separation and protein sequencing have been described previously (Lane et al. 1991).

\section{Photocross-linking of ADI to DNA}

Two DNA probes were synthesized. The 41-mer 5'-GATCCCCGGTGTAGACAGAAGAGGGCTATAAAAGGGGGTGG-3' was annealed to either 5'-CCACCCCCTTTTATAGCCC$3^{\prime}$ (probe 1) or 5'-CCACCCCCTTTTATAGCCCTCTT-3' (probe 2). Partial fill-in reactions were then performed as described (Bartholomew et al. 1991) in near darkness using exonuclease-free Klenow fragment of DNA polymerase and $20 \mu \mathrm{M}$ photocrosslinking nucleotide, 5-[N-(p-azidobenzoyl)-3-aminoallyl]dUMP (kindly provided by G.A. Kassavetis and E.P. Geiduschek) with either $\left[\alpha^{-32} \mathrm{P}\right] \mathrm{dCTP}$ (probe 1) or $\left[\alpha^{32} \mathrm{P}\right] \mathrm{dCTP}$ and $0.1 \mathrm{mM}$ dGTP (probe 2). Following a $15 \mathrm{~min}$ incubation at $37^{\circ} \mathrm{C}$, fully duplex DNA was synthesized by adding $0.5 \mathrm{~mm}$ dGTP, dTTP, dATP, and dCTP to each reaction. Following a second 15 min incubation at $37^{\circ} \mathrm{C}$, the DNAs were ethanol precipitated and purified on a nondenaturing-polyacrylamide gel. Binding reactions were performed using the photocrosslinking probes exactly as for ordinary radiolabeled probes except that the binding reactions contained $5 \mathrm{~mm} \beta$-mercaptoethanol instead of DTT. Following incubation at room temperature for $20 \mathrm{~min}$, samples were irradiated using a handheld short-wave UV light (UVGL-25 mineralight, UVP Inc.) $1.5 \mathrm{~cm}$ above the tops of the open Eppendorf tubes which contained the binding reactions. Half of each reaction was then transferred to a new tube to which was added DTT to $20 \mathrm{~mm}$ (to terminate the cross-linking reaction), and the quenched reaction mixtures were loaded on a mobility retardation gel as described previously (Auble and Hahn 1993). To the remaining half of the reaction mixtures was added $\mathrm{CaCl}_{2}$ to $5 \mathrm{mM}, 1 \mu \mathrm{g}$ of DNase I and 19 units of micrococcal nuclease. The nuclease-treated reactions were incubated for $15 \mathrm{~min}$ at $37^{\circ} \mathrm{C}$, then mixed with an equal volume of SDS sample buffer, boiled and loaded on 6 or $10 \%$ SDS-polyacrylamide gels. The crosslinked products were detected by autoradiography. No crosslinking was detected in the absence of UV light, no crosslinking to TBP alone was detected, and the amount of crosslinked protein was proportional to the dose of UV light for up to two min of irradiation (not shown).

\section{Site-directed mutagenesis}

pKH10, which encodes residues 1255-1867 (613 amino acids) of Motl plus an in-frame c-Myc epitope tag (LEEQKLISEEDLLRKR) at its carboxyl terminus, was constructed by inserting the BamHI fragment of pRS7.1myc (K. Hansen, J. Davis, and J. Thorner, in prep.) into M13mp18. Single-stranded DNA produced from this plasmid was mutagenized using a commercial oligonucleotide-directed in vitro mutagenesis system (Amersham, Version 2.1). The mutagenic oligonucleotide primer, 5'GTGTTTTGAATGAAGGAC-3', was used to introduce a single base change that converted the Asp codon at residue 1408 of Mot 1 to an Asn codon. The complete nucleotide sequence of the 1.2-kb HpaI-EcoNI segment of the resulting plasmid, pKH11, was determined to confirm the presence of the mutation and the absence of extraneous mutations. This fragment was substituted for the corresponding region of MOT1 in pRS7.1myc, to create $\mathrm{pKH} 12$.

In an essentially identical manner, another mutagenic oligonucleotide primer, 5'-GATATGGGTTTGGGTGCTACATTACAAACCATC-3', was used to introduce a single base change that converted the Lys codon at residue 1303 of Mot 1 to an Ala codon. This mutation was verified by sequence analysis and introduced, as a control, into the MOT1 template used for production of Motl by in vitro transcription and translation (see below).

\section{Plasmid constructions}

The ends of the MOT1 coding sequence were adapted for in vitro expression by performing PCR using 5'-ACTTGTTGGATCCTGGCCACGTCACGAGTTTCGAGGCTG-3' and 5'CCAAGAAGGAGCATGGGCAACTAT-3' for amplification of the 5' end and 5'-CTGAGCGCATTGAGAACATTACTC-3' and 5'-CTGACTTGTTGCGGCCGCAGATCTTTATCGTAAAGTTTTGATGAAGGT-3' for amplification of the $3^{\prime}$-end using plasmid pMR13 (Piatti et al. 1992) as the template. Restriction digestion of these products generated a BamHI-PstI 5 '-end fragment and an EcoRV-Notl 3 '-end fragment. Each of these was subcloned into pBluescript II SK $|+|$ and verified by nucleotide sequencing. The $5^{\prime}$-end also contained a $\mathrm{Mscl}$ site suitable for introduction into a $\mathrm{T} 7$ expression vector in which the MOT1 
coding sequence was fused to the CITE translational enhancer (Ranish et al. 1992). The full-length MOT1 sequence or the MOT1 $(K 1303 A)$ mutant were introduced into this $\mathrm{T} 7$ vector by subcloning the engineered 5 ' end, followed by the insertion of the remaining portion of the gene with the Not 13 '-end.

The carboxyl terminus of Mot 1, which includes the domain of homology to Snf2/Swi2, was expressed from the bacteriophage $\mathrm{T} 7$ promoter in E. coli as a fusion to a tract of six histidines by inserting the $1.8-\mathrm{kb}$ BamHI fragment of pRS7.1myc into $\mathrm{pET} 15 \mathrm{~b}$ (Novagen), to yield pKH9. This plasmid produces a protein, Mot1C, whose amino-terminal sequence is MGSSHHHHHHSSGLVPRGSHMLE followed by the carboxy-terminal 613 amino acids of Mot 1 and the c-Myc epitope tag. pKH13 is otherwise identical to pKH9, except it contains the D1408N mutation, and it was constructed by inserting the $1.8-\mathrm{kb} \mathrm{BamHI}$ fragment of pKH12 into pET15b.

To express MOT1 from the GAL1 promoter, PCR was used to introduce a XhoI site just $5^{\prime}$ to the ATG of the MOT 1 coding sequence. This amplification was accomplished using a mutagenic 5' primer (5' -CCCTCGAGCAAATGACGTCACG-3') and a nonmutagenic $3^{\prime}$ primer (5'-CCATTTGATCGGCAGCC-3') which annealed from +61 to +77 . The resulting 88-bp PCR product was digested with $X h o I$ and $B s p E I$ and used to replace the 3-kb XhoI-BspEI fragment of pRS7.1 BgIII [which consists of a MOT1-containing BglII fragment inserted into pRS316 (Davis et al. 1992)], to create pKH2. pKH6 was constructed by inserting the MOT1-containing XhoI-NaeI fragment of pKH2 into YEp352Gal (Benton et al. 1990), which was digested with HindIII, blunt-ended by incubation with T4 DNA polymerase, and then cleaved with SalI. YEp352Gal contains the GAL1-10 promoter, a $2 \mu \mathrm{m}$ origin of replication, and a URA3 marker. To attach the carboxy-terminal c-Myc epitope tag, the $2.9-\mathrm{kb}$ SacI fragment from pKH6 was replaced with the 2.4-kb c-Myc tagcontaining SacI fragment from pRS7.1myc, to produce $\mathrm{pKH} 7$, which overexpresses epitope-tagged MOT1 from the GAL1 promoter. pKH14, which overexpresses c-Myc-tagged MOT1$(D 1408 N)$, was created in an essentially identical fashion by swapping the $2.9-\mathrm{kb}$ SacI fragment of pKH6 with the 2.4-kb SacI fragment from pKH12. pKH20 is identical to $\mathrm{pKH} 7$ and $\mathrm{pKH} 14$, but contains the MOT1(K1303A) mutation.

A LEU2- and $2 \mu \mathrm{m}$ DNA-containing plasmid (pAAH5) expressing yeast TBP (SPT15 gene product) from the $A D H 1$ promoter (Gill and Tiian 1991) was the gift of Dr. Grace Gill. A LEU2- and $2 \mu \mathrm{m}$ DNA-containing plasmid (pSH346) expresses both subunits of yeast TFIIA (TOA1 and TOA2 gene products) from their endogenous promoters $(\mathrm{S}$. Hahn, unpublished results).

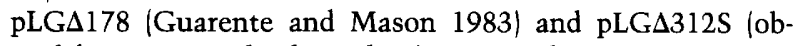
tained from Dr. Michael Botchan) contain the CYC1 promoter from +4 to -178 and from +4 to -312 , respectively, fused to the $E$. coli lacZ gene. The CYC1 promoter in pLG 178 lacks UAS1 and UAS2 (Guarente et al. 1984). pLG $\Delta 312 S$ is identical to pLGA312 (Guarente and Mason 1983), except for the presence of a Sall linker inserted at position -178 (Xhol). pCM100 and pCM100.1 were derived from pSM38 la gift from Dr. Susan Michaelis), which contains the $M F \mathbf{a} 2$ promoter and 32 amino acids of the coding sequence fused to the E. coli lacZ gene. To generate pCM100, a HindIII (blunt-ended by incubation with T4 DNA polymerase) and StuI fragment from pSM38, which contains the MFa2-lacZ fusion from - 675 (numbering from the start site of translation) was ligated into the $X h o I$ (which was converted to flush ends) and StuI sites of pLG $178 \mathrm{~T}$ (Davis et al. 1992), in place of the entire CYC1 cassette. pCM100.1 was generated in a similar way, except that the $M F \mathbf{2} 2$ promoter was truncated to position -191 at the NsiI site (again blunt-ended) before insertion into pLG $\Delta 178 \mathrm{~T}$. This deletion removes the
Mcml binding site and the three most distal Ste 12 binding sites (Dolan et al. 1989). pCM101 and pCM101.1 were derived from pSB234 (a gift from Dr. Joshua Trueheart), which contains the entire FUS1 promoter and 256 amino acids of coding sequence fused to the E. coli lacZ gene. To generate pCM101, a SnaBIStul fragment of the FUS1-lacZ fusion from -402 (numbering from the start site of translation) was inserted into the $\mathrm{XhoI}$ (blunted) and StuI sites of pLGA178T. pCM101.1 was constructed in a simlar way, except that the FUS1 promoter was truncated to position -124 at the Dral site prior to insertion into pLG $\Delta 178 \mathrm{~T}$. This deletion removes all of the sequences required for regulated expression of the FUS1 gene (Hagen et al. 1991). pMH313 and pMH324 (both gifts of Dr. Michael Grunstein) contain, respectively, the entire promoter and upstream region of the PHO5 gene and the region of the PHO5 promoter containing only its TATA-element (Han and Grunstein 1988).

\section{Assay of $\beta$-galactosidase activity}

Enzyme assays were performed, in duplicate or triplicate, as described previously (Rose et al. 1981; Hagen and Sprague 1984). Briefly, yeast cells were grown in minimal medium under selective pressure to an $A_{600} \mathrm{~nm}$ of 1-2, harvested, and whole-cell extracts were prepared by glass bead lysis in the presence of PMSF $(0.1 \mathrm{mg} / \mathrm{ml})$. $\beta$-Galactosidase activity in the extracts was measured as described (Miller 1972) and normalized to the protein concentration of the whole-cell extract. By this procedure, even very low levels of $\beta$-galactosidase could be accurately measured.

\section{Analysis of MOT1 activity}

Mot 1 was made in vitro using a coupled in vitro transcription/ translation system as described by the manufacturer (Promega). Motl activity in the in vitro translation products was assayed by gel mobility retardation experiments as described previously (Auble and Hahn 1993) in $20 \mu$ l reactions which contained between 0.5 and $1.5 \mu l$ of the various in vitro transcription/translation reactions. In vitro transcription by RNA polymerases I, II, and III was performed as described (Colbert and Hahn 1992). Pol I transcription was assayed by $\mathrm{S} 1$ analysis and pol III transcription was assayed by run-off transcription. Pol II transcription employed plasmids which contain the ACT1, HIS4, or CYC1 $(-52)$ TATA elements fused downstream of 3 Gal4 binding sites and transcription was assayed by primer extension. Transcription reactions contained between 30 and $120 \mu \mathrm{g}$ of nuclear extract protein and $250-500 \mathrm{ng}$ of the indicated template DNAs in $25 \mu$ l reactions. Activated transcription was assayed by including $22 \mathrm{ng}$ Gal4-VP16 in the indicated transcription reactions as described previously (Ranish et al. 1992). Transcription of the yeast U6 gene was performed using pCH6 (Brow and Guthrie 1990) exactly as for tRNA and 5S transcription. Because Brfl is depleted in our nuclear extracts, $10 \mathrm{ng}$ of recombinant Brfl was added to all RNA polymerase III transcription reactions. The amount of pol III transcription was proportional to the amount of Brfl added and there was no difference between MOT1 and mot1-1 extracts in pol III transcription when the amount of exogenous Brfl was varied from 5 to 20 ng per reaction. All transcription reactions were repeated three times and the effect of Motl on Pol II transcription was seen in two independently made sets of extracts.

\section{Purification of Mot1C from E. coli}

E. coli strain BL21 (DE3) (Novagen), containing an integrated copy of the T7 RNA polymerase gene expressed from the induc- 
ible lac promoter, was transformed with pET15b, pKH9, or pKH13. Cultures $(500 \mathrm{ml})$ were grown at $30^{\circ} \mathrm{C}$ in TB broth (Sambrook et al. 1989) supplemented with $50 \mu \mathrm{g} / \mathrm{ml}$ of ampicillin to an $A_{600} \mathrm{~nm}$ of 0.5 , and induced with $1 \mathrm{~mm}$ isopropyl-1-thio- $\beta-\mathrm{D}$ galactopyranoside (IPTG) for $90 \mathrm{~min}$. Cells were collected by centrifugation and resuspended in 3 volumes of buffer A $[20 \mathrm{mM}$ Tris-HCL (pH 7.8), $200 \mathrm{~mm} \mathrm{NaCl}, 10 \mathrm{~mm} \mathrm{MgCl}, 1 \mathrm{~mm}$ EDTA, $1 \mathrm{~mm}$ dithiothreitol, $0.2 \mathrm{~mm} 4$-(2-aminoethyl)-benzenesulfonylfluoride-HCL (AEBSF, Calbiochem)] and frozen at $-70^{\circ} \mathrm{C}$. The frozen cells were thawed, and $100 \mu \mathrm{g} / \mathrm{ml} \mathrm{lysozyme} \mathrm{was}$ added. All subsequent steps were performed at $4^{\circ} \mathrm{C}$. Cells were incubated on ice for $30 \mathrm{~min}$ and then sonicated for three 10second pulses, interspersed by cooling on ice. The lysate was then diluted with 8.5 volumes of buffer $\mathrm{A}$ and subject to centrifugation at $20,000 \mathrm{~g}$ for $40 \mathrm{~min}$. A stock of $10 \%$ polyethyleneimine (PEI) was added slowly with stirring to a final concentration of $0.1 \%$ to the supernatant fraction. After $15 \mathrm{~min}$, the insoluble PEI-DNA complexes were removed by centrifugation at $6000 \mathrm{~g}$ for $15 \mathrm{~min}$. Solid ammonium sulfate was added slowly to the clarified extract to $40 \%$ of saturation. After $30 \mathrm{~min}$ of stirring, the extract was subject to centrifugation at $16,000 \mathrm{~g}$ for $30 \mathrm{~min}$. The resulting supernatant solution was then adjusted by addition of more ammonium sulfate to $60 \%$ of saturation. After $30 \mathrm{~min}$ of stirring, the Mot $1 \mathrm{C}$-containing precipitate was collected by centrifugation at $16,000 \mathrm{~g}$ for $30 \mathrm{~min}$. The pellet was redissolved in $20 \mathrm{ml}$ of buffer $\mathrm{B}$ [ $20 \mathrm{mM}$ Tris- $\mathrm{HCl}(\mathrm{pH} 7.8), 500$ $\mathrm{mM} \mathrm{NaCl}, 5 \mathrm{~mm}$ imidazole], and dialyzed against several changes of the same buffer for $12 \mathrm{hr}$. The dialysate was applied at $20 \mathrm{ml} / \mathrm{hr}$ to a column containing $2 \mathrm{ml}$ of iminodiacetateagarose (His-bind, Novagen) equilibrated in buffer B. The column was washed with $20 \mathrm{ml}$ buffer B, then with $12 \mathrm{ml}$ of buffer $B$ containing $60 \mathrm{~mm}$ imidazole. Mot $1 \mathrm{C}$ was eluted in $4 \mathrm{ml}$ of buffer B containing $500 \mathrm{~mm}$ imidazole. The eluate was dialyzed extensively against buffer $\mathrm{C}[20 \mathrm{~mm}$ Tris- $\mathrm{HCl}(\mathrm{pH} 7.8), 200 \mathrm{~mm}$ $\mathrm{NaCl}, 0.1 \mathrm{~mm}$ EDTA, $1 \mathrm{~mm}$ dithiothreitol] and frozen in aliquots at $-70^{\circ} \mathrm{C}$. The preparations of both MotlC and Mot1C(D1408N) were $>90 \%$ pure, as judged by SDS-PAGE and staining with Coomassie blue dye.

\section{ATPase assay}

Samples of Mot1C (140 ng), Mot1C(D1408N) (140 ng), and an equal volume of the eluate from the vector only control (no detectable protein), or an equal volume of buffer $\mathrm{C}$, were incubated, in duplicate, in a total volume of $20 \mu \mathrm{l}$ in $50 \mathrm{~mm}$ BisTris-propane (pH 6.7), $300 \mathrm{mM} \mathrm{NaCl}, 2 \mathrm{mM} \mathrm{MgCl}, 100 \mu \mathrm{g} / \mathrm{ml}$ bovine serum albumin, $0.25 \mathrm{mM} \mathrm{ATP}, 1 \mu \mathrm{Ci}\left[\alpha^{-32} \mathrm{P}\right] \mathrm{ATP}$ for 30 $\min$ at $30^{\circ} \mathrm{C}$. Reactions were terminated by addition of an equal volume of $50 \mathrm{~mm}$ EDTA. Portions $(1 \mu \mathrm{l})$ of each reaction mix ture were spotted onto the origin of PEI-cellulose thin layer plates (Alltech) and subjected to ascending chromatography in 1 $\mathrm{M} \mathrm{LiCl}, 1 \mathrm{M}$ formic acid (Randerath and Randerath 1964). The amount of ADP formed was quantitated using a PhosphorImager (Molecular Dynamics) and normalized to the total radioactivity applied to each lane.

\section{Sequence analysis of Snf2 family members}

Most Snf2/Swi2 family members were identified by BLAST search of the protein and nucleic acid data bases. Selected mem bers were then searched for blocks of related sequences using the MACAW algorithm (Schuler et al. 1991).

\section{Acknowledgments}

We are grateful to Blaine Bartholomew, George Kassavetis, and
Peter Geiduschek for providing 5-[N-(p-azidobenzoyl)-3-aminoallyl-dUMP; to Giovanna Lucchini for plasmid pMR13; to Michael Botchan for plasmids pLG $\Delta 178$ and pLG $\Delta 312 S$; to Jim Geiger for supplying $\mathrm{TBP}_{c}$ to Grace Gill for plasmids pAAH5 and pAAH5-TBP; to Michael Grunstein for plasmids pMH313 and pMH324; to Susan Michaelis for plasmid pSM38; to Renee Robinson for digestion and peptide separation of Motl; to Steve Henikoff for help with the sequence analysis of Snf2 family members; to Tony Weil for allowing us to cite unpublished work; and to Paul Sigler and Steve Henikoff for insightful conversations. Sequence analysis was assisted by the Biocomputing Resource Center at FHCRC. We are also grateful to Steve Henikoff, Trent Colbert, John Kang, Sally Lee, Steve Miller, Jeff Ranish, and Sadia Roberts for comments on the manuscript. This work was supported by a National Institutes of Health Research Grant and a Leukemia Society Scholar Award (to S.H.), by a National Science Foundation Predoctoral Fellowship (to K.E.H.), by Postdoctoral Fellowship (LT-316/92) from the International Human Frontier Science Program Organization (to C.G.F.M.), and by National Institutes of Health Research Grant (GM21841) to J.T.

The publication costs of this article were defrayed in part by payment of page charges. This article must therefore be hereby marked "advertisement" in accordance with 18 USC section 1734 solely to indicate this fact.

\section{References}

Auble, D.T. and S. Hahn. 1993. An ATP-dependent inhibitor of TBP binding to DNA. Genes \& Dev. 7: 844-856.

Bang, D.D., R. Verhage, N. Goosen, J. Brouwer, and P. van de Putte. 1992. Molecular cloning of RAD16, a gene involved in differential repair in Saccharomyces cerevisiae. Nucleic Acids Res. 20: 3925-3931.

Bartholomew, B., G.A. Kassavetis, and E.P. Geiduschek. 1991. Two components of Saccharomyces cerevisiae transcription factor IIIB (TFIIIB) are stereospecifically located upstream of a tRNA gene and interact with the second-largest subunit of TFIIIC. Mol. Cell. Biol. 11: 5181-5189.

Benton, B., W. Eng, J. Dunn, F.W. Studier, R. Sternglanz, and P. Fisher. 1990. Signal-mediated import of bacteriophage T7 RNA polymerase into the Saccharomyces cerevisiae nucleus and specific transcription of target genes. Mol. Cell. Biol. 10: 353-360.

Bork, P. and E.V. Koonin. 1993. An expanding family of helicases within the "DEAD/H" superfamily. Nucleic Acids Res. 21: 751-752.

Brow, D.A. and C. Guthrie. 1990. Transcription of a yeast U6 snRNA gene requires a polymerase III promoter element in a novel position. Genes \& Dev. 4: 1345-1356.

Buratowski, S., S. Hahn, L. Guarente, and P.A. Sharp. 1989. Five intermediate complexes in transcription initiation by RNA polymerase II. Cell 56: 549-561.

Cairns, B.R., Y.-J. Kim, M.H. Sayre, B.C. Laurent, and R.D. Komberg. 1994. A multisubunit complex containing the $S W I 1 /$ ADR6, SWI2/SNF2, SWI3, SNF5, and SNF6 gene products isolated from yeast. Proc. Natl. Acad. Sci. 91: 1950-1954.

Chen, S., R.W. West, J. Ma, S.L. Johnson, H. Gans, and G. Woldehawariat. 1993. TSF1 to TSF6, Required for Silencing the Saccharomyces cerevisiae GAL genes, are global regulatory genes. Genetics 134: 701-716.

Colbert, T. and S. Hahn. 1992. A yeast TFIIB-related factor involved in RNA polymerase III transcription. Genes \& Dev. 6: $1940-1949$.

Collart, M.A. and K. Struhl. 1993. CDC39, an essential nuclear 
protein that negatively regulates transcription and differentially affects the constitutive and inducible HIS 3 promoters. EMBO I. 12: 177-186.

. 1994. NOT1(CDC39), NOT2(CDC36), NOT3, and NOT4 encode a global-negative regulator of transcription that differentially affects TATA-element utilization. Genes \& Dev. 8: 525-537.

Cortes, P., O. Flores, and D. Reinberg. 1992. Factors involved in specific transcription by mammalian RNA polymerase II: Purification and analysis of transcription factor IIA and identification of transcription factor IIJ. Mol. Cell. Biol. 12: 413421.

Davis, J.L., R. Kunisawa, and J. Thorner. 1992. A presumptive helicase (MOT1 gene product) affects gene expression and is required for viability in the yeast Saccharomyces cerevisiae. Mol. Cell. Biol. 12: 1879-1892.

Dolan, J., C. Kirkman, and S. Fields. 1989. The yeast STE12 protein binds to the DNA sequence mediating pheromone induction. Proc. Natl. Acad. Sci. 86: 5703-5707.

Drapkin, R., A. Merino, and D. Reinberg. 1993. Regulation of RNA polymerase II transcription. Curr. Opin. Cell Biol. 5: 469-476.

Durrin, L.K., R.K. Mann, P.S. Kayne, and M. Grunstein. 1991. Yeast histone $\mathrm{H} 4 \mathrm{~N}$-terminal sequence is required for promoter activation in vivo. Cell 65: 1023-1031.

Dynlacht, B.D., T. Hoey, and R. Tjian. 1991. Isolation of coactivators associated with the TATA-binding protein that mediate transcriptional activation. Cell 66: 563-576.

Elfring, L.R., D. Deuring, C.M. McCallum, C.L. Peterson, and J.W. Tamkun. 1994. Identification and characterization of Drosophila relatives of yeast transcriptional activator SNF2/ SWI2. Mol. Cell. Biol. 14: 2225-2234.

Emery, H.S., D. Schild, D.E. Kellogg, and R.K. Mortimer. 1993. Sequence of RAD54, a Saccharomyces cerevisiae gene involved in recombination repair. Gene 104: 103-106.

Eschenlauer, J.B., M.W. Kaiser, V.L. Gerlach, and D.A. Brow. 1993. Architecture of a yeast U6 RNA gene promoter. Mol. Cell. Biol. 13: 3015-3026.

Fernandez, I., M. DeMott, D. Atherton, and S.M. Mische. 1992. Internal protein sequence analysis: Enzymatic digestion for less than $10 \mathrm{mg}$ of protein bound to polyvinylidine difluoride or nitrocellulose membranes. Anal. Biochem. 201: 255-264.

Flores, O., H. Lu, and D. Reinberg. 1992. Factors involved in specific transcription by mammalian RNA polymerase II: Identification and characterization of factor IIH. $J$. Biol. Chem. 267: 2786-2793.

Gill, G. and R. Tiian. 1991. A highly conserved domain of TFIID displays species specificity in vivo. Cell 65: 333-340.

Girdham, C.H. and D.M. Glover. 1991. Chromosome tangling and breakage at anaphase result from mutations in lodestar, a Drosophila gene encoding a putative nucleoside triphosphate-binding protein. Genes \& Dev. 5: 1786-1799.

Goodrich, J.A., T. Hoey, C.J. Thut, A. Admon, and R. Tjian. 1993. Drosophila TAF40 interacts with both a VP16 activation domain and the basal transcription factor TFIIB. Cell 75: 519-530.

Guarente, L. and T. Mason. 1983. Heme regulates transcription of the CYC1 gene of $S$. cerevisiae via an upstream activation site. Cell 32: 1279-1286.

Guarente, L., B. Lalonde, P. Gifford, and E. Alani. 1984. Distinctly regulated tandem upstream activation sites mediate catabolite repression of the $C Y C 1$ gene of $S$. cerevisiae. Cell 36: 503-511.

Hagen, D.C. and G.F. Sprague, Jr. 1984. Induction of the yeast a-specific $S T E 3$ gene by the peptide pheromone a-factor. $J$. Mol. Biol. 178: 835-852.
Hagen, D.C., G. McCaffrey, and G.F. Sprague, Jr. 1991. Pheromone response elements are necessary and sufficient for basal and pheromone-induced transcription of the FUS1 gene of Saccharomyces cerevisiae. Mol. Cell. Biol. 11: 29522961.

Hahn, S., S. Buratowski, P.A. Sharp, and L. Guarente. 1989. Identification of a yeast protein homologous in function to the mammalian general transcription factor, TFIIA. EMBO $J$. 8: 3379-3382.

Han, M. and M. Grunstein. 1988. Nucleosome loss activates yeast downstream promoters in vivo. Cell 55: 1137-1145.

Happel, A.M., M.S. Swanson, and F. Winston. 1991. The SNF2, SNF5 and SNF6 genes are required for Ty transcription in Saccharomyces cerevisiae. Genetics 128: 69-77.

Henikoff, S. 1993. Transcriptional activator components and poxvirus DNA-dependent ATPases comprise a single family. Trends Biochem. Sci. 18: 291-292.

Hirschhorn, J.N., S.A. Brown, C.D. Clark, and F. Winston. 1992. Evidence that SNF2/SWI2 and SNF5 activate transcription in yeast by altering chromatin structure. Genes \& Dev. 6: 2288-2298.

Hoey, T., R.O.J. Weinzierl, G. Gill, J.-L. Chen, B.D. Dynlacht, and R. Tjian. 1993. Molecular cloning and functional analysis of Drosophila TAF110 reveals properties expected of coactivators. Cell 72: 247-260.

Inostroza, J.A., F.H. Mermelstein, I.H. Ha, W.S. Lane, and D. Reinberg. 1992. Dr1, a TATA-binding protein-associated phosphoprotein and inhibitor of class II transcription. Cell 70: $477-489$.

Joazeiro, C.A.P., G.A. Kassavetis, and E.P. Geiduschek. 1994. Identical components of yeast transcription factor IIIB are required and sufficient for transcription of TATA box-containing and TATA-less genes. Mol. Cell. Biol. 14: 27982808.

Johnson, R.E., S.T. Henderson, T.D. Petes, S. Prakash, M. Bankmann, and L. Prakash. 1992. Saccharomyces cerevisiae RAD5-encoded DNA repair protein contains DNA helicase and zinc-binding sequence motifs and affects the stability of simple repetitive sequences in the genome. Mol. Cell. Biol. 12: 3807-3818.

Kadonaga, J.T. 1990. Assembly and disassembly of the Drosophila RNA polymerase II complex during transcription. $J$. Biol. Chem. 265: 2624-2631.

Khavari, P.A., C.L. Peterson, J.W. Tamkun, D.B. Mendel, and G.R. Crabtree. 1993. BRGl contains a conserved domain of the SWI2/SNF2 family necessary for normal mitotic growth and transcription. Nature 366: 170-174.

Kokubo, T., D.-W. Gong, J.C. Wootton, M. Horikoshi, R.G. Roeder, and Y. Nakatami. 1994. Molecular cloning of Drosophila TFIID subunits. Nature 367: 484-487.

Kretzschmar, M., M. Meisterernst, and R.G. Roeder. 1993. Identification of human DNA topoisomerase I as a cofactor for activator-dependent transcription by RNA polymerase II. Proc. Natl. Acad. Sci. 90: 11508-11512.

Lane, W.S., A. Galat, M.W. Harding, and S.L. Schreiber. 1991. Complete amino acid sequence of the FK506 and rapamycin binding protein, FKBP, isolated from calf thymus. J. Prot. Chem. 10: 151-160.

Laurent, B.C. and M. Carlson. 1992. Yeast SNF2/SWI2, SNF5, and SNF6 proteins function coordinately with the gene-specific transcriptional activators GAL4 and Bicoid. Genes \& Dev. 6: $1707-1715$.

Laurent, B.C., M.A. Treitel, and M. Carlson. 1991. Functional interdependence of the yeast SNF2, SNF5 and SNF6 proteins in transcriptional activation. Proc. Natl. Acad. Sci. 88: $2687-2691$. 
Laurent, B.C., X. Yang, and M. Carlson. 1992. An essential Saccharomyces cerevisiae gene homologous to SNF2 encodes a helicase-related protein in a new family. Mol. Cell. Biol. 12: 1893-1902.

Laurent, B.C., I. Treich, and M. Carlson. 1993. The yeast SNF2/ SWI2 protein has DNA-stimulated ATPase activity required for transcriptional activation. Genes \& Dev. 7: 583-591.

Laybourn, P.J. and J.T. Kadonaga. 1992. Threshold phenomena and long-distance activation of transcription by RNA polymerase II. Science 257: 1682-1685.

Lewis, L.K., M.E. Jenkins, and D.W. Mount. 1992. Isolation of DNA damage-inducible promoters in Escherichia coli: Regulation of $p o l B(\operatorname{din} A)$, din $G$ and $\operatorname{din} H$ by LexA repressor. J. Bacteriol. 174: 3377-3385.

Lieberman, P.M., M.C. Schmidt, C.C. Kao, and A.J. Berk. 1991. Two distinct domains in the yeast transcription factor IID and evidence for a TATA box-induced conformational change. Mol. Cell. Biol. 11: 63-74.

Maldonado, E., I. Ha, P. Cortes, L. Weis, and D. Reinberg. 1990. Factors involved in specific transcription by mammalian RNA polymerase II: Role of transcription factors IIA, IID, and IIB during formation of a transcription-competent complex. Mol. Cell. Biol. 10: 6335-6347.

Meisterernst, M. and R.G. Roeder. 1991. Family of proteins that interact with TFIID and regulate promoter activity. Cell 67: $557-567$.

Meisterernst, M., A.L. Roy, H.M. Lieu, and R.G. Roeder. 1991. Activation of class II gene transcription by regulatory factors is potentiated by a novel activity. Cell 66: 981-993.

Merino, A., K.R. Madden, W.S. Lane, J.J. Champoux, and D. Reinberg. 1993. DNA topoisomerase I is involved in both repression and activation of transcription. Nature 365: 227232.

Miller, J.H. 1972. Experiments in molecular genetics. Cold Spring Harbor Laboratory, Cold Spring Harbor, New York.

Nagawa, F. and G.R. Fink. 1985. The relationship between the "TATA" sequence and transcription initiation sites at the HIS4 gene of Saccharomyces cerevisiae. Proc. Natl. Acad. Sci. 82: 8557-8561.

Okabe, I., L.C. Bailey, O. Attree, S. Srinivasan, J.M. Perkel, B.C. Laurent, M. Carlson, D.L. Nelson, and R.L. Nussbaum. 1992. Cloning of the human and bovine homologs of SNF2/ SWI2: A global activator of transcription in yeast. Nucleic Acids Res. 20: 4649-4655.

Pause, A. and N. Sonenberg. 1992. Mutational analysis of a DEAD box RNA helicase: The mammalian translation initiation factor eIF-4A. EMBO I. 11: 2643-2654.

Peterson, C.L. and I. Herskowitz. 1992. Characterization of the yeast SWI1, SWI2, and SWI3 genes, which encode a global activator of transcription. Cell 68: 573-583.

Piatti, S., R. Tazzi, A. Pizzagalli, P. Plevani, and G. Lucchini. 1992. Control of DNA synthesis genes in budding yeast: Involvement of the transcriptional modulator MOT1 in the expression of the DNA polymerase alpha gene. Chromosoma 102: S107-S113.

Poon, D. and P.A. Weil. 1993. Immunopurification of yeast TATA-binding protein and associated factors. J. Biol. Chem. 268: 15325-15328.

Randerath, K. and E. Randerath. 1964. Ion-exchange chromatography of nucleotides on poly-(ethyleneimine)-cellulose thin layers. J. Chromatog. 16: 111-125.

Ranish, J.A., W.S. Lane, and S. Hahn. 1992. Isolation of two genes that encode subunits of the yeast transcription factor IIA. Science 255: 1127-1129.

Rose, M., M.J. Casaban, and D. Botstein. 1981. Yeast genes fused to $\beta$-galactosidase from Escherichia coli can be expressed normally in yeast. Proc. Natl. Acad. Sci. 79: 2460-2464.

Sambrook, J., E.F. Fritsch, and T. Maniatis. 1989. Molecular cloning: A laboratory manual. Cold Spring Harbor Laboratory, Cold Spring Harbor, New York.

Sayre, M.H., H. Tschochner, and R.D. Kornberg. 1992. Reconstitution of transcription with five purified initiation factors and RNA polymerase II from Saccharomyces cerevisiae. $I$. Biol. Chem. 267: 23376-23382.

Schuler, G.D., S.F. Altschul, and D.J. Lipman. 1991. A workbench for multiple alignment construction and analysis. Proteins Struct. Func. Genet. 9: 180-190.

Sherman, F., G.R. Fink, and J.B. Hicks. 1986. Laboratory course manual for methods in yeast genetics. Cold Spring Harbor Laboratory, Cold Spring Harbor, New York.

Soininen, R., M. Schoor, U. Henseling, C. Tepe, B. KistersWoike, J. Rossant, and A. Gossler. 1992. The mouse enhancer trap locus 1 (Etl-1): A novel mammalian gene related to Drosophila and yeast transcriptional regulator genes. Mech. Dev. 39: 111-123.

Sung, P., D. Higgins, L. Prakash, and S. Prakash. 1988. Mutation of lysine 78 to arginine in the yeast RAD3 protein abolishes its ATPase and DNA helicase activities but not the ability to bind ATP. EMBO /. 7: 3263-3269.

Takada, R., Y. Nakatani, A. Hoffmann, T. Kokubo, S. Hasegawa, R.G. Roeder, and M. Horikoshi. 1992. Identification of human TFIID components and direct interaction between a 250-kD polypeptide and the TATA box-binding protein (TFIIDt). Proc. Natl. Acad. Sci. 89: 11809-11813.

Tamkun, J.W., R. Deuring, M.P. Scott, M. Kissinger, A.M. Pattatucci, T.C. Kaufman, and J.A. Kennision. 1992. brahma: A regulator of Drosophila homeotic genes structurally related to the yeast transcriptional activator SNF2/SWI2. Cell 68: $561-572$.

Toelstra, C., A. van Gool, J. de Wit, W. Vermeulen, D. Bootsma, and J.H.J. Hoeijmakers. 1992. ERCC6, a member of a subfamily of putative helicases, is involved in Cockayne's Syndrome and preferential repair of active genes. Cell 71: 939953.

Towbin, H., T. Staehelin, and J. Gordon. 1979. Electrophoretic transfer of proteins from polyacrylamide gels to nitrocellulose sheets: Procedures and some applications. Proc. Natl. Acad. Sci. 76: 4350-4354.

Tyree, C.M., C.P. George, L.M. Lira-DeVito, S.L. Wampler, M.E. Dahmus, L. Zawel, and J.T. Kadonaga. 1993. Identification of a minimal set of proteins that is sufficient for accurate initiation of transcription by RNA polymerase II. Genes \& Dev. 7: 1254-1265.

Van Dyke, M.W., R.G. Roeder, and M. Sawadogo. 1988. Physical analysis of transcription preinitiation complex assembly on a class II gene promoter. Science 241: 1335-1338.

Winston, F. and M. Carlson. 1992. Yeast SNF/SWI transcriptional activators and the SPT/SIN chromatin connection. Trends Genet. 8: 387-391.

Workman, J.L. and R.E. Kingston. 1992. Nucleosome core displacement in vitro via a metastable transcription factor-nucleosome complex. Science 258: 1780-1784.

Yamashita, I. 1993. Isolation and characterization of the SUD1 gene, which encodes a global repressor of core promoter activity in Saccharomyces cerevisiae. Mol. Gen. Genet. 241: 616-626.

Zawel, L. and D. Reinberg. 1993. Initiation of transcription by RNA Polymerase II: A multi-step process. Prog. Nucleic Acid Res. 44: 67-108. 


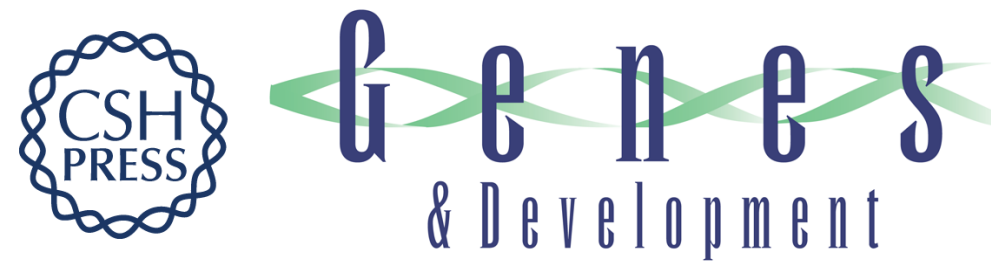

\section{Mot1, a global repressor of RNA polymerase II transcription, inhibits TBP binding to DNA by an ATP-dependent mechanism.}

D T Auble, K E Hansen, C G Mueller, et al.

Genes Dev. 1994, 8:

Access the most recent version at doi:10.1101/gad.8.16.1920

References This article cites 78 articles, 39 of which can be accessed free at:

http://genesdev.cshlp.org/content/8/16/1920.full.html\#ref-list-1

License

Email Alerting

Service

Receive free email alerts when new articles cite this article - sign up in the box at the top right corner of the article or click here.

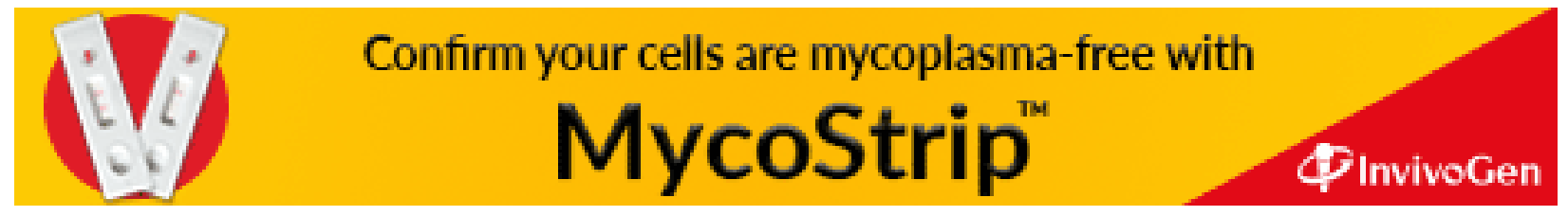

